\title{
Retrieval of intrinsic mesospheric gravity wave parameters using lidar and airglow temperature and meteor radar wind data
}

\author{
Robert Reichert ${ }^{1}$, Bernd Kaifler ${ }^{1}$, Natalie Kaifler ${ }^{1}$, Markus Rapp ${ }^{1,2}$, Pierre-Dominique Pautet ${ }^{3}$, Michael J. Taylor ${ }^{3}$, \\ Alexander Kozlovsky ${ }^{4}$, Mark Lester ${ }^{5}$, and Rigel Kivi ${ }^{6}$ \\ ${ }^{1}$ Deutsches Zentrum für Luft- und Raumfahrt, Institut für Physik der Atmosphäre, Oberpfaffenhofen, Germany \\ ${ }^{2}$ Meteorologisches Institut, Ludwig-Maximilians-Universität, Munich, Germany \\ ${ }^{3}$ Center for Atmospheric and Space Sciences and Physics Department, Utah State University, Logan, Utah, USA \\ ${ }^{4}$ Sodankylä Geophysical Observatory, University of Oulu, Sodankylä, Finland \\ ${ }^{5}$ Department of Physics and Astronomy, University Leicester, Leicester, UK \\ ${ }^{6}$ Space and Earth Observation Centre, Finnish Meteorological Institute, Sodankylä, Finland
}

Correspondence: Robert Reichert (robert.reichert@dlr.de)

Received: 25 February 2019 - Discussion started: 3 June 2019

Revised: 20 August 2019 - Accepted: 24 September 2019 - Published: 19 November 2019

\begin{abstract}
We analyse gravity waves in the uppermesosphere, lower-thermosphere region from highresolution temperature variations measured by the Rayleigh lidar and $\mathrm{OH}$ temperature mapper. From this combination of instruments, aided by meteor radar wind data, the full set of ground-relative and intrinsic gravity wave parameters are derived by means of the novel WAPITI (Wavelet Analysis and Phase line IdenTIfication) method. This WAPITI tool decomposes the gravity wave field into its spectral component while preserving the temporal resolution, allowing us to identify and study the evolution of gravity wave packets in the varying backgrounds. We describe WAPITI and demonstrate its capabilities for the large-amplitude gravity wave event on 16-17 December 2015 observed at Sodankylä, Finland, during the GW-LCYCLE-II (Gravity Wave Life Cycle Experiment) field campaign. We present horizontal and vertical wavelengths, phase velocities, propagation directions and intrinsic periods including uncertainties. The results are discussed for three main spectral regions, representing small-, medium- and large-period gravity waves. We observe a complex superposition of gravity waves at different scales, partly generated by gravity wave breaking, evolving in accordance with a vertically and presumably also horizontally sheared wind.
\end{abstract}

\section{Introduction}

The impact of atmospheric gravity waves (GWs) on the energy and momentum budget, especially in the uppermesosphere, lower-thermosphere (MLT) region has long been recognized (Lindzen, 1981; Holton, 1982, 1983; Vincent and Reid, 1983). However, many mechanisms are not fully understood today, for example regarding generation, intermittency, and interactions or breaking of GWs (see Fritts and Alexander, 2003, for a review). Understanding of these processes requires detailed case studies with a complete description of intrinsic gravity wave parameters and the atmospheric background. A well-established and capable technique to observe mesospheric GWs is the imaging of $\mathrm{OH}$ layer emissions, which provides compelling detail of the spatial and temporal characteristics of GWs (Swenson and Mende, 1994; Taylor et al., 1995; Nakamura et al., 2003; Suzuki et al., 2007; Vargas et al., 2016). Analysis methods applied to images of the $\mathrm{OH}$ layer in order to infer horizontal wavelengths, ground-relative wave periods and phase speeds, and propagation directions include filtering with selected bandwidths, e.g. to enhance $\mathrm{GW}$ signatures, fitting routines to specific (e.g. cyclic) wave structures (e.g. Hapgood and Taylor, 1982), time-difference and correlation techniques (Swenson et al., 1999; Tang et al., 2003), cross-spectral and wavelet analysis (Frey et al., 2000), three-dimensional fast Fourier transform (Matsuda et al., 2014), and maximum entropy methods (Sedlak et al., 2016). In order to retrieve hor- 
izontal wavelengths larger than the field of view (FOV) of the imager, Takahashi et al. (2009) and Fritts et al. (2014) analysed keogram representations of airglow imager data. In addition to process studies, also large-period observations of $\mathrm{OH}$ layer emissions with imaging instruments are employed to derive statistics and seasonal variations in GW parameters at different locations (Walterscheid et al., 1999; Nakamura et al., 1999; Suzuki et al., 2004; Li et al., 2016, 2018; Shiokawa et al., 2009).

The detection of GWs by means of $\mathrm{OH}$ layer intensity observations depends on the (usually unknown) width and height of the $\mathrm{OH}$ layer as well as the GW period and vertical wavelength (Gardner and Taylor, 1998; Dunker, 2018). To obtain intrinsic periods, $\mathrm{OH}$ imaging data are often combined with meteor radar observations of the ambient wind (e.g. Nyassor et al., 2018). Mangognia et al. (2016) proposed a multi-channel instrument to deduce vertical wavelengths which must otherwise be determined from the dispersion relation or in combination with other observation techniques. Especially sodium lidar instruments, providing vertical soundings of vertical wind and temperature in the sodium layer located above the $\mathrm{OH}$ layer, were essential in order to derive vertical wavelengths, phase speeds and momentum fluxes in the MLT region (Swenson et al., 1999; Jia et al., 2016). This technique allowed for the study of GW dispersion, refraction or breaking in the MLT region (Smith et al., 2005; Yuan et al., 2016). Isler et al. (1997) and Hecht et al. (1997) also incorporated wind measurements by MF radar to investigate ducting, evanescence and breaking of GWs.

Lidar soundings of the middle atmosphere are ideally suited for studying gravity waves at high vertical and temporal resolution (e.g. Hostetler and Gardner, 1994; Lu et al., 2009; Baumgarten et al., 2015; Zhao et al., 2017; Fritts et al., 2018). In the stratosphere and lower mesosphere, climatologies of gravity wave potential energy densities were derived from lidar backscatter (Wilson et al., 1991; Sivakumar et al., 2006; Sica and Argall, 2007; Thurairajah et al., 2010; Alexander et al., 2011; Mzé et al., 2014; Kaifler et al., 2015; Kogure et al., 2018). Due to limitations in power and/or efficiency of Rayleigh lidars, often a gap remains in the upper mesosphere between the top altitude of Rayleigh-lidar temperature profiles and coincident sodium lidar measurements. Recent developments in Rayleigh-lidar technology allow for high-resolution temperature and GW measurements at altitudes above $\sim 85 \mathrm{~km}$ within the $\mathrm{OH}$ layer (Kaifler et al., 2017, 2018). Also, modern OH imaging instruments utilize different $\mathrm{OH}$ emission lines to perform spectroscopy in order to derive the spatial temperature field, thus facilitating synergy of $\mathrm{OH}$ layer imaging and vertical lidar soundings that has not been possible before.

In recognition of the prospects of multi-instrument approaches for middle atmosphere GW studies, several field campaigns combining a large number of ground-based and airborne instruments have been undertaken in recent years, e.g. the GW-LCYCLE-1 (Gravity Wave Life Cycle Exper- iment) campaign in northern Scandinavia in 2013 (Wagner et al., 2017; Witschas et al., 2017) and the DEEPWAVE campaign in New Zealand in 2014 (Fritts et al., 2016). During the winter of 2015-2016, the season when GWs of high amplitude were able to propagate from the troposphere to the mesosphere, the GW-LCYCLE-II aircraft campaign took place in northern Scandinavia. During and beyond the campaign period, the high-powered Compact Rayleigh $\mathrm{Au}-$ tonomous Lidar (CORAL), the Advanced Mesospheric Temperature Mapper (AMTM) and an All-Sky Interferometric Meteor Radar (SKiYMET) were co-located at Sodankylä, Finland. For the first time, common-volume observations at resolutions below $1 \mathrm{~h}$ can thus be exploited for detailed studies of gravity waves in the MLT region. We develop a consistent analysis method to derive the full set of GW parameters by means of wavelet analysis and a phase line identification (WAPITI - Wavelet Analysis and Phase line IdenTIfication) algorithm and apply it to the combined data set. Wavelet analysis is a well-established method in atmospheric science in general but also with respect to the study of atmospheric GWs. It is applied to in situ, remote-sensing and satellite observations, and reanalysis data, with the goal of characterizing GW parameters, deriving global maps, or studying generation processes in the troposphere or stratosphere and turbulence generation by breaking GWs (Stockwell et al., 1996; Alexander and Barnet, 2007; Zhang et al., 2001; Dörnbrack et al., 2018; Koch et al., 2005). The key advantage is the preserved temporal resolution, allowing for the detection of spatially and temporally localized wave packets. We present a systematic spectral decomposition of AMTM keograms (a two-dimensional representation of pixel columns and rows evolving with time; see, e.g. Taylor et al., 2009) and lidar data in order to detect and characterize GW packets observed by the three instruments. Using this technique, co-existing, interacting and evolving GW packets can be studied.

We demonstrate our analysis for the GW event on 1617 December 2015, when large-amplitude propagating GWs were observed in the mesosphere. The instruments are described in Sect. 2 together with their respective data sets. The WAPITI algorithm developed to derive GW parameters like horizontal and vertical wavelengths, propagation directions, and phase velocities for waves of different scales is described in Sect. 3. It is applied to the data sets of 16-17 December 2015 in Sect. 4, followed by a discussion of the spectral characteristics of the identified waves in Sect. 5. Conclusions are given in Sect. 6.

\section{Instruments and data sets}

During the GW-LCYCLE-II campaign in winter 20152016, three instruments were co-located at Sodankylä, Finland $\left(67.4^{\circ} \mathrm{N}, 26.6^{\circ} \mathrm{E}\right)$, collecting complementary data sets. CORAL provided vertical profiles of middle-atmospheric temperature and GW perturbations $(27-98 \mathrm{~km})$. The AMTM 
imager detected GWs in the horizontal plane at the altitude of the $\mathrm{OH}$ layer $(\sim 86 \mathrm{~km})$. The Sodankylä-Leicester Ionospheric Coupling Experiment (SLICE) meteor radar provided horizontal wind measurements in the upper mesosphere $(82-98 \mathrm{~km})$. Simultaneous observations of all three instruments were obtained during 78 nights between September 2015 and April 2016. Here we selected the night of 1617 December 2015, when large-amplitude GWs occurred in order to demonstrate our retrieval of the full set of GW parameters.

\subsection{CORAL}

CORAL was built by the German Aerospace Center (DLR) and installed at the Finnish Meteorological Institute Sodankylä site in September 2015. CORAL is a Rayleigh backscatter lidar for the middle atmosphere. It incorporates a $12 \mathrm{~W}$ laser operated at $532 \mathrm{~nm}$ wavelength as a transmitter, a $63 \mathrm{~cm}$ diameter receiving telescope and two heightcascaded receiving channels equipped with avalanche photodiodes run in the photon-counting mode (Kaifler et al., 2017, 2018). CORAL was designed with the capability for remote control and automatic operation in order to maximize operation hours. During 6 months of operation, $492 \mathrm{~h}$ of high-quality data were collected during nighttime. In the absence of aerosols, the received photon counts are directly proportional to the density of the atmosphere. Following Hauchecorne and Chanin (1980) we infer atmospheric temperatures by top-down integration of atmospheric density profiles assuming hydrostatic equilibrium. This is first performed for the nightly average profile smoothed with a filter of $\sim 2 \mathrm{~km}$ width using SABER measurements as a seed value at the $100-110 \mathrm{~km}$ altitude. Then, in an iterative manner, temperature profiles of subsequently higher resolutions of $120,60,30,20$ and $10 \mathrm{~min}$ are obtained by seeding at their top altitudes with the respective lower-resolution profiles. For this study, we use temperature data at the $2070 \mathrm{~m}$ vertical and $10 \mathrm{~min}$ time resolution computed on a grid of $90 \mathrm{~m} \times 1 \mathrm{~min}$, which is intrinsic to the temperature retrieval. Above $\sim 92 \mathrm{~km}$ the temporal resolution gradually decreases from $10 \mathrm{~min}$ to $2 \mathrm{~h}$ due to longer integration times. The uncertainties in absolute temperatures caused by photon noise and in part by the temperature seeding process amount to $0.3 \mathrm{~K}$ between 25 and $50 \mathrm{~km}, 1.6 \mathrm{~K}$ between 50 and $75 \mathrm{~km}$, and $9.9 \mathrm{~K}$ between 75 and $100 \mathrm{~km}$. Figure 1 shows the temperature measurement of 16-17 December 2015. We see the stratopause at $60 \mathrm{~km}$, with strong wave activity above in the mesosphere and periods of about $4 \mathrm{~h}$. A more detailed description is given in Sect. 3 .

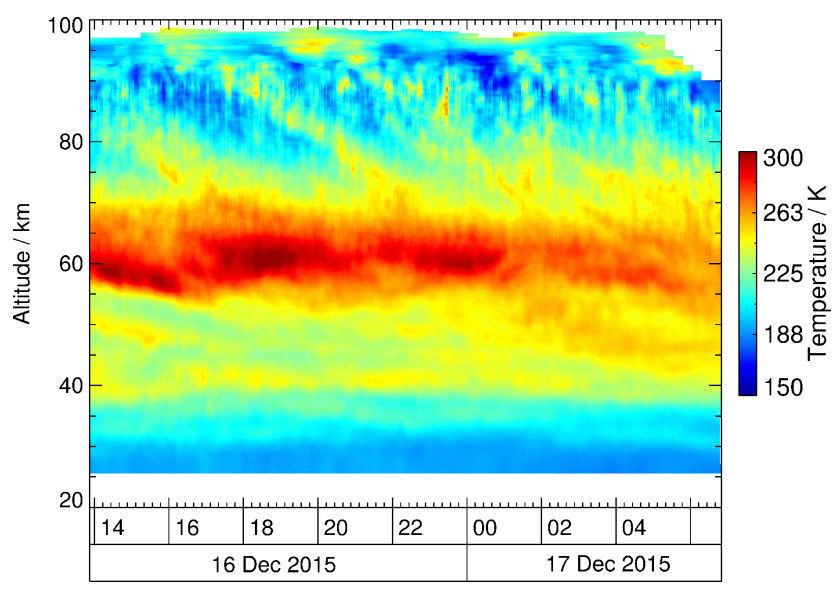

Figure 1. Time-altitude section of temperature obtained by CORAL on 16-17 December 2015. Above $\sim 92 \mathrm{~km}$, the temporal resolution decreases gradually, from $10 \mathrm{~min}$ to $2 \mathrm{~h}$.

\subsection{AMTM}

The AMTM was built by Utah State University and yields temperature maps based on detected IR radiation originating from the $\mathrm{OH}$ layer (Pautet et al., 2014; Fritts et al., 2014). This layer is commonly described as Gaussian-shaped, with an average peak altitude of $86.8 \pm 2.6 \mathrm{~km}$ and a full width at half maximum (FWHM) of $8.6 \pm 3.1 \mathrm{~km}$, although the local height and thickness can vary (Baker and Stair Jr, 1988). The temperature is a function of the brightness ratio of two spectral lines in the Meinel $(3,1)$ rotation-vibration hydroxyl bands, namely $B\left[P_{1}(2)\right] / B\left[P_{1}(4)\right]$. The spatial and temporal resolution of the AMTM is $625 \mathrm{~m}$ at zenith and $\sim 30 \mathrm{~s}$, and the field of view is about $200 \mathrm{~km} \times 160 \mathrm{~km}$. Temperature uncertainties are of the order of $1-2 \mathrm{~K}$ for clear sky conditions. Due to strong contamination by sunlight, the AMTM operates only during darkness. To gain better insight into the temporal evolution of the temperature maps, we analyse AMTM data in the keogram representation. The AMTM's FOV is oriented in the cardinal directions, as shown in Fig. 2a. Concatenating pixel rows (columns) of successive temperature maps at $\sim 30 \mathrm{~s}$ resolution results in a south-north (westeast) keogram projecting GWs onto this particular direction. AMTM data for 16-17 December 2015 in this representation are shown in Fig. 2b. The position of the lidar laser beam is in the zenith of the AMTM's FOV, as indicated by the dashed lines in Fig. 2b. For the analysis, we interpolated the AMTM data sets on a $1 \mathrm{~min}$ grid to be able to compare them with lidar data and to reduce noise.

\subsection{Meteor radar}

SLICE is a SKiYMET meteor radar (MR) and provides measurements of horizontal wind speeds in the altitude range of $82-98 \mathrm{~km}$ at a vertical and temporal resolution of $2.7 \mathrm{~km} \times 1 \mathrm{~h}$ (Lukianova et al., 2018). The MR is operated 
(a)

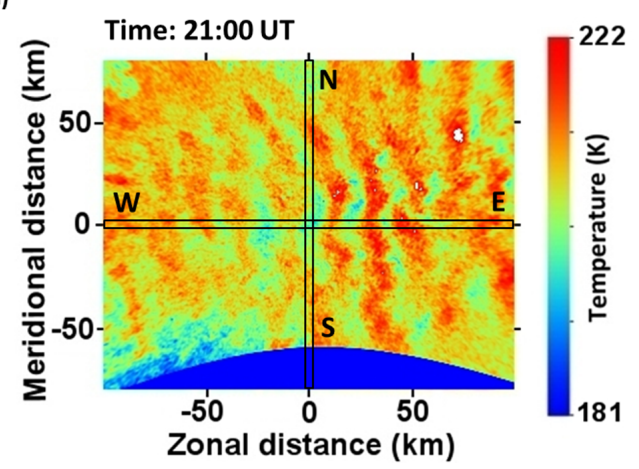

(b)

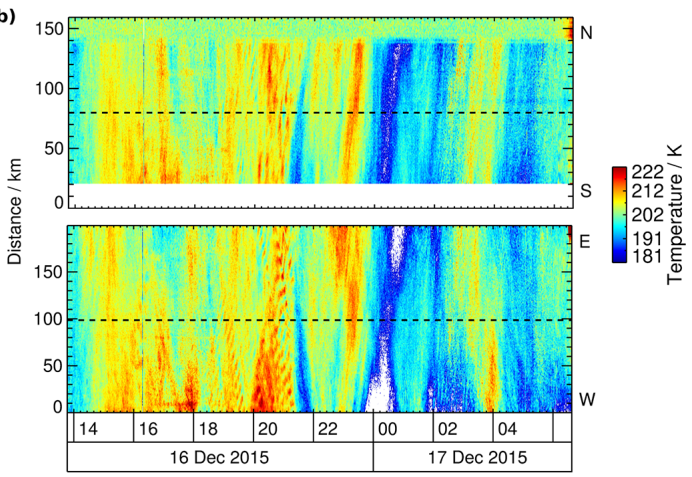

Figure 2. (a) AMTM temperature map at 21:00 UT on 16 December 2015 with indicated pixel rows and columns used for keogram representation. (b) South-north keogram of AMTM temperature measurements (top) and west-east keogram (bottom) on 16-17 December 2015. The central dashed lines indicate the position of the lidar laser beam.

by the Sodankylä Geophysical Observatory. Wind data are retrieved from the line-of-sight velocity of the ionized meteor trails detected in a FOV of about $300 \mathrm{~km}$ in diameter (Hocking et al., 2001). Figure $3 \mathrm{a}-\mathrm{c}$ show zonal and meridional wind speeds as well as the wind direction during the night of 16-17 December 2015. The wind field is complex, with both vertical and horizontal reversals and shears on small scales. We therefore expect time-varying parameters of GWs observed by CORAL and the AMTM.

\section{Analysis}

In the following, we present our newly developed WAPITI algorithm used to retrieve observed and intrinsic GW parameters based on three complementary data sets at mesospheric altitudes. From AMTM temperature data, we obtain horizontal wavelengths as well as propagation directions at the altitude of the $\mathrm{OH}$ layer. Vertical wavelengths and directionality of the vertical propagation are derived from CORAL vertical temperature profiles. In combination with meteor radar wind speeds, we estimate intrinsic periods. As a cross check, we use the dispersion relation to retrieve vertical wavelengths based on horizontal wavelengths and intrinsic periods and compare the result with vertical wavelengths retrieved from lidar data.

\subsection{Spectral filtering of temperature data}

The AMTM provides data in a temporally resolved keogram representation in horizontal dimensions $x$ and $y$, while CORAL observations yield time series of temperature at different altitudes $z$. Following Torrence and Compo (1998) we apply a wavelet transformation with 6th-order Morlet wavelets to all the time series within the common FOV of both instruments, i.e. for the lidar position at $\mathrm{OH}$ layer altitudes.
The discrete periods used for the wavelet transformations are given by

$$
\tau_{j}=\frac{4 \pi \cdot \mathrm{d} t \cdot 2^{j / 8+1}}{\omega_{0}+\sqrt{2+\omega_{0}^{2}}} .
$$

Here, the non-dimensional frequency, $\omega_{0}=6$, is the order of the wavelet. The time resolution is represented by $\mathrm{d} t=$ $1 \mathrm{~min}$, and $j$ is the index of the wavelet, ranging from 0 to 71 , selecting periods between $2 \mathrm{~min}$ and $16.2 \mathrm{~h}$. The resulting wavelet spectra show spectral power based on squared amplitudes of temperature perturbations as a function of the time and observed period (Fig. 4). The cone of influence (COI), inside of which edge effects due to the finite time series may result in an underestimation of spectral power, is indicated by a hatched region. Significance levels of $95 \%, 50 \%$ and $20 \%$ calculated relative to red-noise spectra are shown as contour lines to highlight potential GW structures within each spectrum. To assess the effect of temperature uncertainties in the wavelet spectrum, we perform Monte Carlo simulations. We add 100 Gaussian-distributed samples of white noise with a standard deviation of the temperature measurement uncertainty to the actual temperature time series and apply a wavelet transformation. One standard deviation range is shown with dashed lines together with the global wavelet spectra (Fig. 4b, c, e).

Alexander (1998) applies instrumental filter functions to model data in order to make GW spectra from model output and measurements comparable. In order to compare wavelet spectra of CORAL and the AMTM, we weighted lidar temperatures between 78 and $95 \mathrm{~km}$ with a Gaussian distribution with a FWHM of $8.6 \mathrm{~km}$ centred at $86.8 \mathrm{~km}$. Figure $4 \mathrm{a}$ shows the natural logarithm of the squared absolute value of the spectral amplitude of the CORAL temperature time series averaged over the $\mathrm{OH}$ layer. An impression of the spectral variability with height is given in Fig. 4c, where we present global wavelet spectra at different altitudes. The Monte Carlo simulation revealed increasing noise levels in global wavelet 

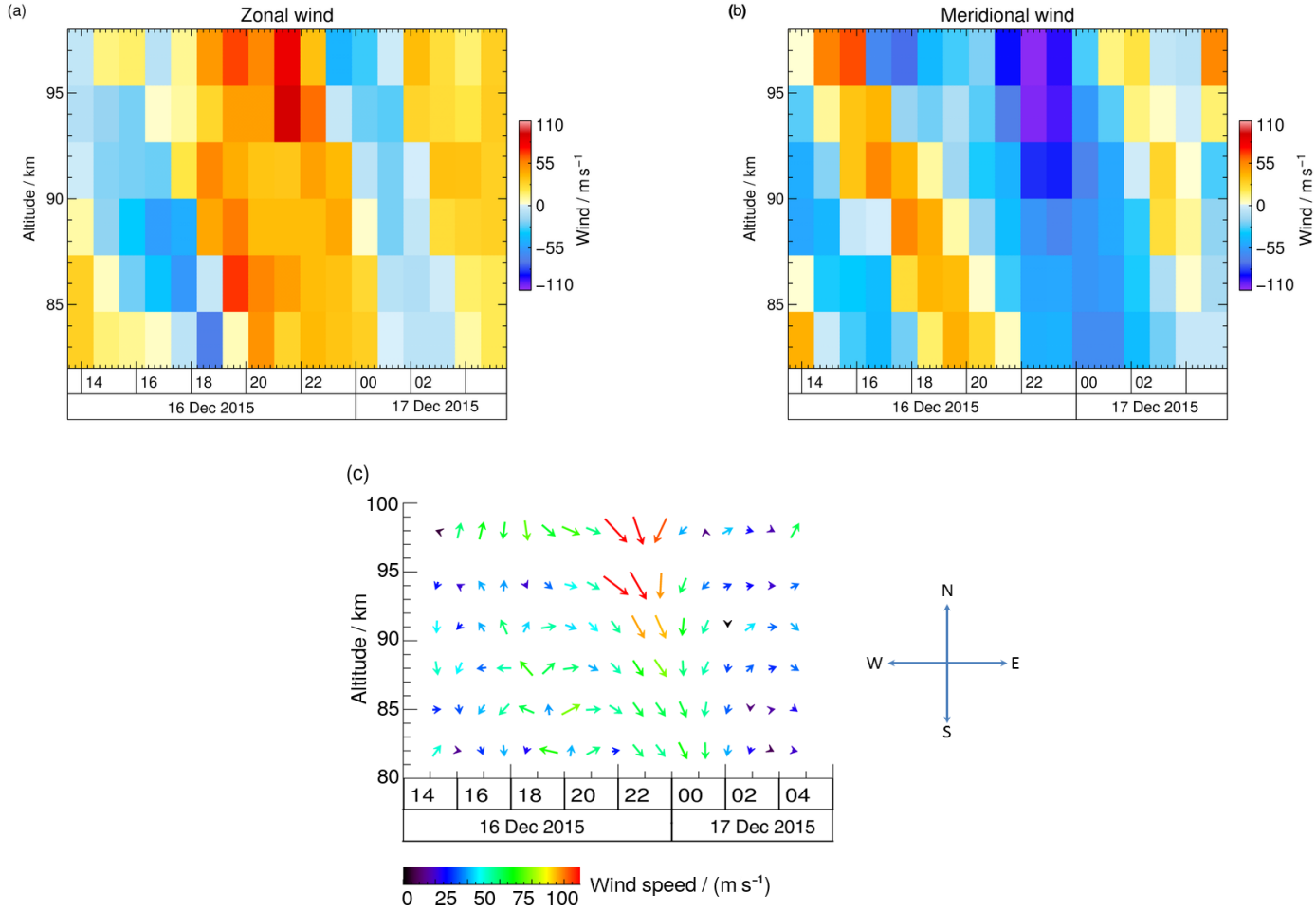

Figure 3. (a) Zonal wind, (b) meridional wind and (c) wind direction observed by the SLICE meteor radar on 16-17 December 2015.

spectra with smaller periods, especially below $0.5 \mathrm{~h}$. Hence, we decided to focus on the spectral range between the 0.5 and $8 \mathrm{~h}$ observed period. Figure $4 \mathrm{~d}$ displays the wavelet spectrum for the zenith time series of AMTM temperature (dashed lines in Fig. 2b). A detailed description of the spectra is given in Sect. 4.

We analyse wavelet power at 32 discrete periods in which $\tau_{j}>30 \mathrm{~min}$ and reconstruct the respective temperature perturbations for each spatial dimension $x, y$ (AMTM) and $z$ (CORAL). If GWs with periods $\tau_{j}$ are present in the data set, they are observed as a pattern of phase lines of significant amplitude in the wavelet reconstruction. Two examples are shown in Fig. 5b and c. Periods not supported by the data exhibit very small reconstructed temperature perturbations. From the progression of phase lines, we derive phase velocities in each direction.

\subsection{Phase line identification}

In order to detect phase lines in the reconstructed data, we need to identify points belonging to the same phase, e.g. points along wave crests or troughs. They are detected by looking for a change of sign in the derivative of the temperature time series with respect to time. In order to allow for a robust phase line detection, the wavelet reconstructions are smoothed with a boxcar window with a width of $5 \mathrm{~km}$ in the spatial domain for keograms and $2 \mathrm{~km}$ for vertical profiles and $\tau_{j} / 4$ in the time domain. The identified extrema are con- nected in space in order to determine the phase angle in the zenith position by a linear fit to phase lines.

Figure 5a illustrates the phase line detection of our WAPITI algorithm. To isolate a number of $i$ phase lines, we find points of time $t_{i}(r)$ which follow the position of wave crests and troughs in each data set. For example, the first maximum in the zenith time series occurs at $t_{1}\left(r_{0}\right)$. In the time series adjacent to $r_{0}$ we find the maximum which is closest to $t_{1}$ and at most $\Delta t<\tau_{j} / 2$ apart. This maximum is identified as belonging to the phase line $i=1$. This step is repeated for all $r$ values within the window $\Delta r=$ $12 \mathrm{~km} \mathrm{~h}^{-1} \tau_{j}+20 \mathrm{~km}$ for keograms and $\Delta r=8.6 \mathrm{~km}$ for the lidar data set. The window width for lidar data contains the average thickness of the $\mathrm{OH}$ layer. We choose a dynamic range for keograms; i.e. the range increases with the selected period $\tau_{j}$ because larger structures tend to be more coherent. In a second step we fit a linear function $t_{i}(r)=a_{i} r+b_{i}$ to the detected phase lines and calculate the $1 \sigma$ uncertainty estimates $\Delta a_{i}$ and $\Delta b_{i}$. The coefficient $a_{i}$ has the dimension of an inverse velocity, while $b_{i}$ is a constant time parameter.

Examples of reconstructed time series and detected phase lines are shown in Fig. $5 b$ and c. Increased amplitudes indicate the presence of GWs with the selected $\tau_{j}$. The matching of temperature reconstructions and estimated phase lines is very good for short as well as for large periods. 


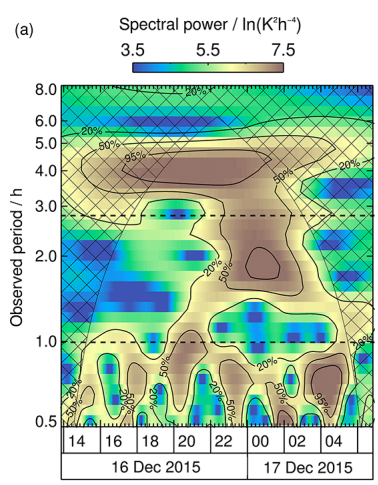

(b)
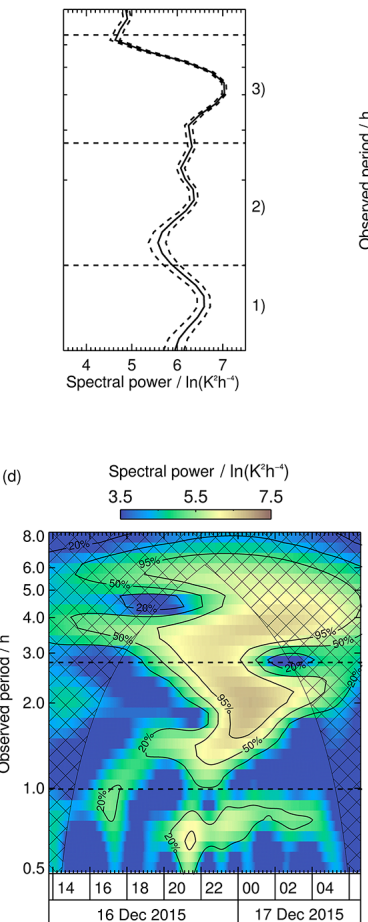

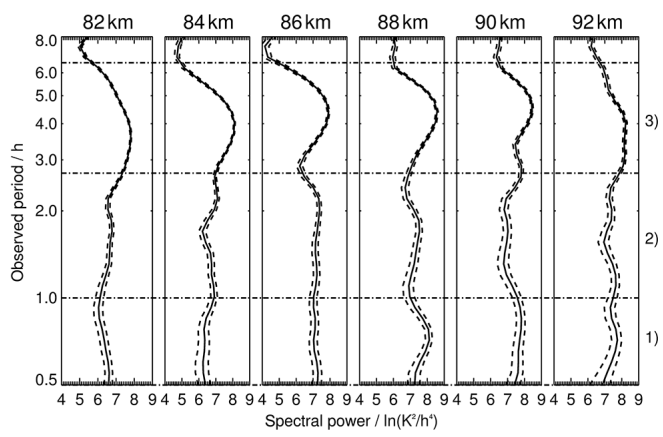

(e)

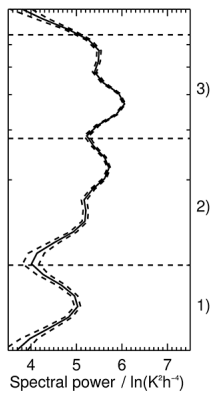

Figure 4. (a) Wavelet power spectrum of Gaussian-weighted lidar time series and (b) global wavelet spectrum including standard deviation. (c) CORAL global wavelet spectra including standard deviations for six altitudes between 82 and $92 \mathrm{~km}$. (d) Wavelet power spectrum of the zenith time series of the AMTM and (e) global wavelet spectrum including standard deviation. The hatched areas mark the COI. Solid lines indicate the $20 \%, 50 \%$ and $95 \%$ significance levels. Three period ranges with dominant waves are indicated by numbers on the right axis.

\subsection{Horizontal wavelength and direction of propagation}

The observed horizontal wavelength $\lambda_{\mathrm{h}}$ can be retrieved directly from the $\mathrm{OH}$ airglow images. However, in this case, the maximum wavelength is of the order of the dimension of the FOV $(\sim 200 \mathrm{~km})$. Larger horizontal wavelengths can be retrieved from the detected phase lines from above. Then, $\lambda_{\mathrm{h}}$ is given by the product of the phase velocity $c$ and the period of the GW $\tau$. Hence, in order to retrieve the phase velocities $c_{i}$ in each direction at time $t_{i}\left(r_{0}\right)$, we calculate the inverse of the derivative of the linear fit $t_{i}(r)$ with respect to space,

$c_{i}\left(t_{i}\left(r_{0}\right)\right)=\left(\frac{\mathrm{d} t_{i}(r)}{\mathrm{d} r}\right)^{-1}=\frac{1}{a_{i}}$.

To estimate the uncertainty of the phase velocity $\Delta c_{i}$, we calculate the propagated error of $\Delta a_{i}$ given by

$\Delta c_{i}\left(t_{i}\left(r_{0}\right)\right)=c_{i}\left(t_{i}\left(r_{0}\right)\right)^{2} \Delta a_{i}$.

We now have an estimate for phase velocity and its uncertainty at discrete points in time. As an approximation, we assume that the fitted parameters vary linearly between these discrete points. Consequently, $a_{i}, b_{i}, \Delta a_{i}$ and $\Delta b_{i}$ are linearly interpolated. To simplify the equations, we drop the explicit time dependence from now on in the notation. We obtain wavelengths $\lambda_{x}$ and $\lambda_{y}$ by

$\lambda_{x}=\tau c_{x}$,

$\lambda_{y}=\tau c_{y}$.

Uncertainties for these and following quantities are given in Appendix A. We consider no uncertainty for the period of the wavelet transformation defined in Eq. (1). We also note that uncertainties in the spectral amplitude of the wavelet spectrum do not lead to uncertainties in the reconstructed period but to uncertainties in the amplitude of the reconstructed signal. Thus, structures are conserved.

The horizontal wavelength is determined by $\lambda_{x}$ and $\lambda_{y}$ (Eq. 5), as illustrated in Fig. 6a:

$\lambda_{\mathrm{h}}=\frac{\lambda_{y} \lambda_{x}}{\sqrt{\lambda_{y}^{2}+\lambda_{x}^{2}}}$.

As the phase velocities can have positive and negative signs, $\lambda_{\mathrm{h}}$ can be positive or negative depending on the propagation direction. However, the direction of propagation is usually expressed as an angle relative to north, thus making the information encoded in the sign of the horizontal wavelength 
(a)

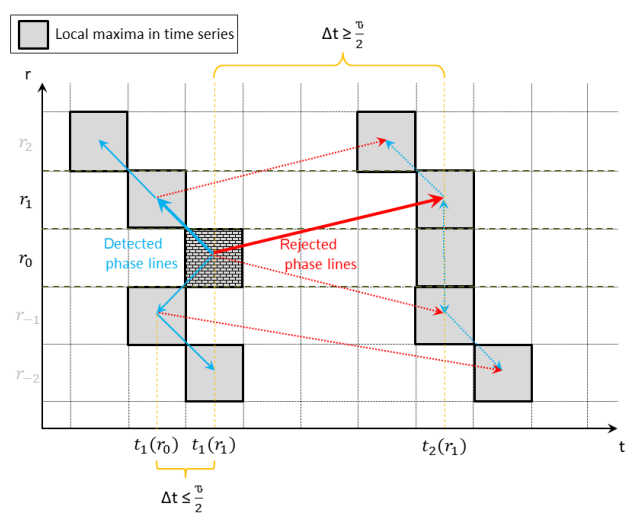

(b)

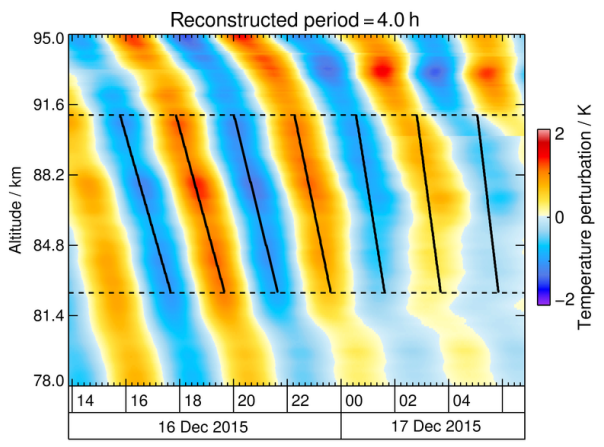

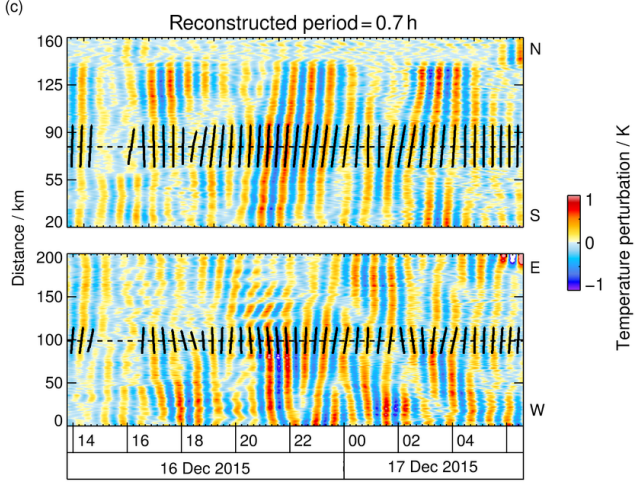

Figure 5. (a) Sketch illustrating the phase line detection of the WAPITI algorithm. The grid represents data resolved in space and time. Grey boxes represent local temperature maxima in each time series $r_{i}$. Blue arrows point to adjacent maxima that are affiliated with a phase line. Red arrows point to adjacent maxima that are too far away and therefore do not belong to the considered phase line. Solid arrows describe the first step in the algorithm, and sketched time intervals refer to these solid arrows. Dotted arrows describe further steps of the algorithm. (b) Phase line identification applied to reconstructed temperature perturbations in lidar data with a period of $4.0 \mathrm{~h}$ and (c) in airglow data with a period of $0.7 \mathrm{~h}$. Solid black lines are fitted linear functions.

(a)

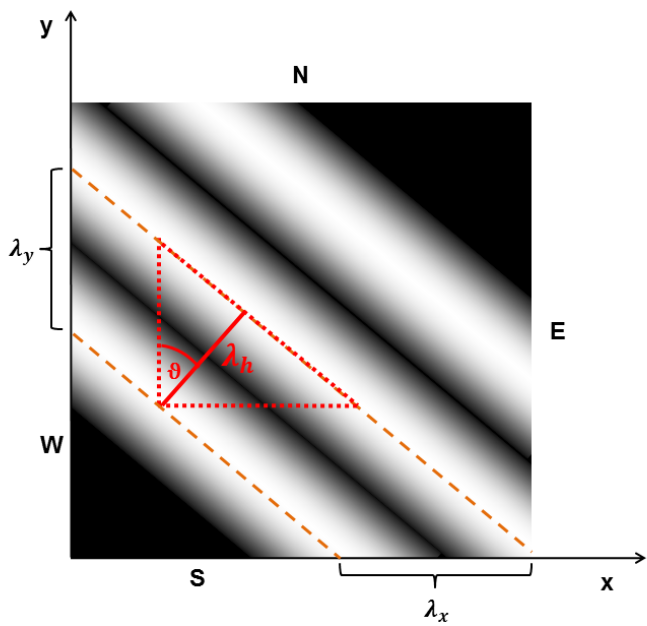

(b)

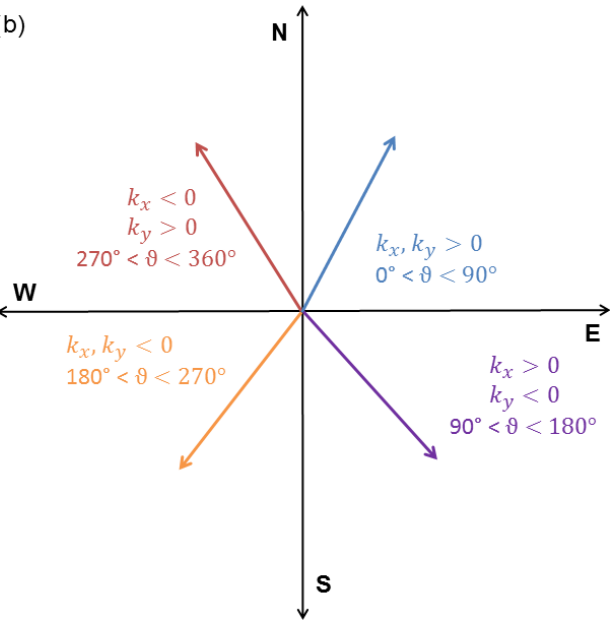

Figure 6. (a) Sketch to illustrate the relation between wavelengths. $\lambda_{\mathrm{h}}$ is defined as the height of a right triangle (red) with sides $\lambda_{x}$ and $\lambda_{y}$. (b) Definition of the propagation angle. The horizontal direction of propagation is given by the relation of wavelengths in the $x$ and $y$ direction. Coloured arrows describe different propagation directions. 
redundant. Following this convention, we drop the sign and consider absolute values only.

The propagation angle $\theta$ is defined clockwise starting at $0^{\circ}$, with $\theta=0^{\circ}$ being north. Figure $6 \mathrm{~b}$ illustrates propagation directions in the horizontal plane. For $\lambda_{x}>0$ the wave propagates eastward and $\theta=\frac{\pi}{2}+\tan ^{-1}\left(-\frac{\lambda_{x}}{\lambda_{y}}\right)$. For $\lambda_{x}<0$ the wave propagates westward and $\theta=\frac{3}{2} \pi+\tan ^{-1}\left(-\frac{\lambda_{x}}{\lambda_{y}}\right)$. With knowledge of wave propagation and wind direction, we calculate the background wind $u_{0}$ in the direction of propagation, which is needed for the estimation of intrinsic parameters.

\subsection{Intrinsic period}

The observed phase velocity of a GW is given by $c=c_{\mathrm{I}}+u_{0}$ (Nappo, 2002), with $c_{\mathrm{I}}$ being the intrinsic phase velocity and $u_{0}$ being the background wind. Furthermore, $c_{\mathrm{I}}=\frac{\lambda_{\mathrm{h}}}{\tau_{\mathrm{I}}}$, with $\tau_{\mathrm{I}}$ being the intrinsic period and $\lambda_{h}$ being the horizontal wavelength. If we rearrange this definition and solve for the intrinsic period $\tau_{\mathrm{I}}$, we obtain

$\tau_{\mathrm{I}}=\frac{\lambda_{\mathrm{h}}}{c-u_{0}}$.

The background wind projected onto the GW propagation direction is calculated as

$u_{0}(\theta)=U \sin (\theta)+V \cos (\theta)$,

with $U$ and $V$ being the zonal and meridional wind components. Both components are weighted with a Gaussian distribution over an altitude range of $82-95 \mathrm{~km}$, with a FWHM of $8.6 \mathrm{~km}$ centred at $86.8 \mathrm{~km}$ and averaged over this range. For $u_{0}=0$, the intrinsic period equals the observed period. Assuming a constant horizontal wavelength, i.e. no horizontal gradients in the horizontal wind (Marks and Eckermann, 1995), the intrinsic period becomes larger than the observed period if the background wind is oriented in the same direction as the observed phase velocity and $0<u_{0}<c$. The intrinsic period becomes smaller than the observed period if the background wind is oriented against the observed phase velocity and $u_{0}<0$. The intrinsic frequency $\Omega$ of vertically propagating GWs is limited to $f<\Omega<N$ (Nappo, 2002), with $N$ being the Brunt-Väisälä frequency and $f$ being the Coriolis parameter. We estimate the range for $\tau_{\mathrm{I}}$ at $5 \mathrm{~min}<$ $\tau_{\mathrm{I}}<13 \mathrm{~h}$ for typical values of $N$ and $f$ at $67.4^{\circ} \mathrm{N}$. For $u_{0}=c$ the intrinsic period becomes infinite, and the wave reaches a critical level and breaks. The uncertainty for the intrinsic period is given in Appendix A.

\subsection{Vertical wavelength}

The vertical wavelength $\lambda_{z}$ is derived using two independent methods. From the phase line detection applied to lidar data, we derive the vertical phase velocity $c_{z}$. Multiplying it by the period $\tau$ yields the vertical wavelength $\lambda_{z}$. The uncertainty
$\Delta \lambda_{z}=\tau \Delta c_{z}$ is given by the $1 \sigma$ uncertainty estimate from the linear fit applied during the phase line detection. Like the observed horizontal phase velocity, the observed vertical phase velocity can have both signs as well. For upward-propagating waves, $c_{z}<0$, and for downward-propagating waves, $c_{z}>0$. According to Dörnbrack et al. (2017) this condition holds for $u_{0}>-c_{\mathrm{I}}$. Otherwise waves appear to be propagating upward in lidar data, while they are in reality propagating downward and vice versa.

The second approach uses the dispersion relation and the parameters retrieved from AMTM data to derive a vertical wavelength. In Sect. 4 we show both results for $\lambda_{z}$, which we discuss in Sect. 5. The dispersion relation reads

$m^{2}=\frac{N^{2}}{\left(c-u_{0}\right)^{2}}+\frac{u_{0}^{\prime \prime}}{\left(c-u_{0}\right)}-\frac{1}{H_{\mathrm{s}}} \frac{u_{0}^{\prime}}{\left(c-u_{0}\right)}-\frac{1}{4 H_{\mathrm{s}}^{2}}-k^{2}$,

where $m$ is the vertical wave number and $H_{\mathrm{S}}$ is the scale height (Nappo, 2002). Primes indicate the derivative with respect to $z$. We substitute $c_{\mathrm{I}}=\frac{\lambda_{\mathrm{h}}}{\tau_{\mathrm{I}}}=c-u_{0}$, and when we solve the dispersion relation for $\lambda_{z}$, we get

$\lambda_{z}=\frac{2 \pi}{\sqrt{\left(\frac{N \tau_{\mathrm{I}}}{\lambda_{\mathrm{h}}}\right)^{2}+\frac{u_{0}^{\prime \prime} \tau_{\mathrm{I}}}{\lambda_{\mathrm{h}}}-\frac{u_{0}^{\prime} \tau_{\mathrm{I}}}{H_{\mathrm{s}} \lambda_{\mathrm{h}}}-\left(\frac{1}{2 H_{\mathrm{s}}}\right)^{2}-\left(\frac{2 \pi}{\lambda_{\mathrm{h}}}\right)^{2}}}$.

We derived expressions for $\lambda_{\mathrm{h}}$ and $\tau_{\mathrm{I}}$ in previous sections. $H_{\mathrm{S}}$ is defined as $H_{\mathrm{s}}=R T / g$, with $R=287 \mathrm{~J} \mathrm{~kg}^{-1} \mathrm{~K}^{-1}$ being the universal gas constant for dry air and $g=9.81 \mathrm{~m} \mathrm{~s}^{-2}$ being the acceleration due to gravity. The Brunt-Väisälä frequency $N$ is defined as

$N=\sqrt{\frac{g}{T}\left(\frac{\partial T}{\partial z}+\frac{g}{c_{\mathrm{p}}}\right)}$,

with $c_{\mathrm{p}}=1.005 \mathrm{~kJ} \mathrm{~kg}^{-1} \mathrm{~K}^{-1}$ being the specific heat capacity for air at constant pressure. We calculate the nightly mean of $N$ in the altitude range of 82-91 km based on background temperature profiles which are obtained by low-pass filtering of lidar temperature profiles following Ehard et al. (2015). We derive $N=0.0202 \pm 0.0016 \mathrm{~s}^{-1}$ and $H_{\mathrm{s}}=5.60 \pm 0.08 \mathrm{~km}$ at $\mathrm{OH}$ layer altitudes. We assume $N$ and $H_{\mathrm{s}}$ to be constant and also assume a uniform wind in the horizontal plane, i.e. a constant $\lambda_{\mathrm{h}}$. The derivatives of horizontal wind with respect to altitude $u_{0}^{\prime}$ and $u_{0}^{\prime \prime}$ are determined between 82 and $95 \mathrm{~km}$ and averaged over this altitude range in the same way as for the Gaussian-weighted average of the background wind (see Sect. 3.4). In the next section, we apply our WAPITI algorithm to GWs observed on the 16-17 December 2015.

\section{Results}

During the night of 16-17 December 2015, strong GW signals were detected by the AMTM and CORAL above Sodankylä, Finland. The wavelet spectra (Fig. 4) reveal a broad 
distribution of observed periods with high spectral power throughout the night. In the lidar data, we find three regions with significance levels $>95 \%$. The most prominent region lies at the $\sim 4 \mathrm{~h}$ observed period between 17:00 and 02:00 UT. Another region lies close to the $2 \mathrm{~h}$ observed period at 00:00 UT, while the third region consists of three peaks between the 0.5 and $1.0 \mathrm{~h}$ observed period and 23:0005:00 UT (Fig. 4a). In AMTM data we see GW amplitudes with significance levels $>95 \%$ from 19:00 UT until the end of the night. Dominant GWs exhibit observed periods in the range of $1.5-6.5 \mathrm{~h}$ (Fig. 4d). We calculate global wavelet spectra (Fig. 4b, c, e) and divide them into three regions based on local maxima in spectral power. Region (I) is defined from the 30-60 min observed period and contains small-period GWs. The second region ranges from 1.0 to $2.8 \mathrm{~h}$. Region (III) comprises periods of $2.8-6.5 \mathrm{~h}$. We restrict our analysis to periods below $6.5 \mathrm{~h}$ due to the finite data sets and the respective COI. Amplitudes in AMTM data at longer wavelengths are too small for reliable detection of phase lines by our algorithm. The insensitivity of our method to changes at scales above $6.5 \mathrm{~h}$ at the same time ensures our focus on GWs and attributes the action of tides and planetary waves to the GW background. We keep in mind that both may interact and alter the GW parameters. In general, the spectra of AMTM and CORAL are in good agreement. However, amplitudes in the lidar spectrum are larger.

As stated in Sect. 3 we retrieved wavelengths and propagation angles for 32 reconstructed periods such that the GW parameters can be displayed as a function of the time and observed period. To give an overview, the retrieved parameters in the three spectral regions defined above are organized in probability density distributions next to the full spectra. We do a kernel density estimation (KDE) for this purpose. Each value is represented as a normalized Gaussian distribution, with a standard deviation given by its uncertainty. Finally all Gaussian distributions are added and divided by the number of values taken into account in order to normalize the probability density distribution. Values with small uncertainties are represented as peaks with a small FWHM, while values with large uncertainties are represented as flat and broad peaks in the distribution. In comparison to a standard histogram the KDE takes the uncertainty of each value into account. Hence, the distribution is independent of a chosen bin size, and each peak is reliable. In the background we show the total density distribution of each parameter comprising all values within the $20 \%$ significance contour line in light grey. This enables us to investigate how each spectral region contributes to the total distribution. Additionally we hatched the parts of each distribution which show parameters within the COI to be aware of their contribution. Figure $7 \mathrm{a}$ and $\mathrm{b}$ show horizontal wavelengths retrieved from AMTM data. We see a large variation in $\lambda_{\mathrm{h}}$, ranging from 75 to $2000 \mathrm{~km}$. The uncertainties lie of the order of a few percent in significant regions. Figure $7 \mathrm{c}$ shows horizontal propagation directions of the waves identified by the WAPITI algorithm. The density distributions in
Fig. 7d show waves predominantly propagating in northward directions. Figure $8 \mathrm{a}$ and $\mathrm{b}$ display the wind every wave is exposed to, i.e. wind speed in the direction of propagation. Most waves propagate against the mean flow, resulting in negative wind speeds of up to $-80 \mathrm{~m} \mathrm{~s}^{-1}$. Figure $8 \mathrm{c}$ and $\mathrm{d}$ show estimated intrinsic periods based on wind speeds. Due to the motion in opposite directions, the majority of intrinsic periods are Doppler-shifted to larger observed periods. Vertical wavelengths retrieved from lidar data are shown in Fig. 9a and $b$, where we find values of $6-50 \mathrm{~km}$. A background wind field varying in space and time has an impact on the observed period of GWs and hence affects the temperature reconstructions. Therefore phase lines in our data sets are bent, and we find locally large wavelengths. Vertical wavelengths between 1 and $50 \mathrm{~km}$ are retrieved using the dispersion relation (Fig. 9c and d).

Tables 1 and 2 summarize the range of GW parameters of a number of likely GW packets across the three spectral ranges for the discussion.

\section{Discussion}

Before we discuss the presented results of our analysis, we want to point out the assumptions and limitations in this case study. As we mentioned in Sect. 2, the $\mathrm{OH}$ layer peak altitude is on average located at $86.6 \mathrm{~km}$ and has a thickness of $8.6 \mathrm{~km}$. Because no satellite soundings of $\mathrm{OH}$ are available for the period of the case study, we use these climatological values. However, we note that the actual peak altitude and thickness of the $\mathrm{OH}$ layer may deviate from the climatological mean, leading to uncertainties in the wavelet spectra, as we average Gaussian-weighted lidar temperatures over the altitude range of the $\mathrm{OH}$ layer. The same holds true for averaged wind data. Wind speeds are systematically averaged over an area of $\sim 300 \mathrm{~km}$ in diameter. We take this into account by asserting large uncertainties to the retrieved wind speeds (see Appendix A). Another limitation is that lidar measurements are restricted to the centre of the $\mathrm{OH}$ imager's FOV, with decreasing resolution towards higher altitudes. We highlighted the congruent altitude range of the three instruments' data. However, resolutions and observational volumes differ. We chose a $20 \%$ significance level to maximize the overlapping areas in lidar and AMTM wavelet spectra, especially for short periods, as Fig. 5c has proven that also at this significance level, detectable and coherent structures can be retrieved.

Dörnbrack et al. (2017) showed that upward-propagating waves appear to be propagating downward in lidar data for $u_{0}<-c_{\mathrm{I}}$. In the majority of cases this condition is not fulfilled, and the intrinsic vertical propagation direction matches the observed vertical propagation direction (upward-downward). 
Table 1. GW parameters derived from AMTM and SLICE data for selected dominant GW packets. The ranges describe the FWHM of peaks in each density distribution. Values for $\tau$ and time refer to identified peaks in the propagation direction.

\begin{tabular}{|c|c|c|c|c|c|c|c|c|}
\hline Region & $\tau / \mathbf{h}$ & Time / UT & $\theta 1^{\circ}$ & $\lambda_{h} / \mathrm{km}$ & $\tau_{I} / \mathbf{h}$ & $c_{I} / \mathrm{m} \mathrm{s}^{-1}$ & $u_{0} / \mathrm{ms}^{-1}$ & $\lambda_{z} / \mathrm{km}$ \\
\hline \multirow{3}{*}{ I) } & $0.5-0.8$ & $20-22$ & $312-336$ & \multirow{3}{*}{$114-166$} & \multirow{3}{*}{$0.4-0.5$} & \multirow{3}{*}{$70-121$} & \multirow{3}{*}{$-48--26$} & \multirow{3}{*}{$7-50$} \\
\hline & $0.6-0.8$ & $22-04$ & $19-38$ & & & & & \\
\hline & $0.8-1.0$ & 17 & $125-162$ & & & & & \\
\hline \multirow{2}{*}{ II) } & $1.2-2.8$ & $20-02$ & $358-35$ & \multirow{2}{*}{$443-747$} & \multirow{2}{*}{$1.1-1.8$} & \multirow{2}{*}{$72-150$} & \multirow{2}{*}{$-65--28$} & \multirow{2}{*}{$5-54$} \\
\hline & $1.2-1.6$ & $19-22$ & $88-177$ & & & & & \\
\hline \multirow{5}{*}{ III) } & \multirow{2}{*}{$3.5-4.5$} & \multirow{2}{*}{$18-02$} & $284-289$ & \multirow{5}{*}{$739-1032$} & \multirow{5}{*}{$2.5-3.1$} & \multirow{5}{*}{$21-113$} & \multirow{5}{*}{$-65-43$} & \multirow{5}{*}{$1-32$} \\
\hline & & & $299-319$ & & & & & \\
\hline & $4.5-6.0$ & $20-01$ & $71-88$ & & & & & \\
\hline & \multirow{2}{*}{$2.8-3.5$} & \multirow{2}{*}{$18-01$} & $7-26$ & & & & & \\
\hline & & & $33-50$ & & & & & \\
\hline
\end{tabular}

Table 2. Vertical wavelengths derived from CORAL data. The ranges describe the FWHM of peaks in the density distribution.

\begin{tabular}{|c|c|c|c|c|}
\hline Region & $\tau / \mathrm{h}$ & Time / UT & $\lambda_{z} / \mathrm{km}$ & Propagation direction \\
\hline \multirow{2}{*}{ I) } & \multirow{2}{*}{$0.5-1.0$} & \multirow{2}{*}{ Whole night } & $17-25$ & Upward \\
\hline & & & $10-43$ & Downward \\
\hline \multirow{4}{*}{ II) } & $1.0-1.5$ & $20-22$ & \multirow{2}{*}{$11-36$} & Upward \\
\hline & $1.0-2.0$ & $02-06$ & & Upward \\
\hline & 2.5 & $02-03$ & $6-8$ & Upward \\
\hline & $1.2-2.8$ & $22-02$ & $16-45$ & Downward \\
\hline \multirow{3}{*}{ III) } & $3.5-6.0$ & $18-02$ & $19-22$ & Upward \\
\hline & $2.8-3.5$ & $18-22$ & $12-14$ & Upward \\
\hline & $2.8-3.5$ & $22-03$ & $24-40$ & Downward \\
\hline
\end{tabular}

\subsection{Small-period gravity waves}

Spectral region (I) comprises GWs with observed periods between 0.5 and $1.0 \mathrm{~h}$. Comparison of the global wavelet spectra of CORAL (Fig. 4b) and the AMTM (Fig. 4e) yields coinciding peaks at the $\sim 0.7 \mathrm{~h}$ observed period. The difference in spectral amplitudes mentioned above is reflected in the levels of significance. The spectra in Fig. 4c show an increase in spectral amplitude with altitude. As long as no wave breaking occurs, we expect increasing amplitudes with altitude due to decreasing density. From comparing both spectra, we are confident to see the same GWs with both instruments but with different sensitivities at different times.

We find that the majority of horizontal wavelengths lie between 114 and $166 \mathrm{~km}$ (Fig. 7b). When we compare the distribution of region (I) with the total density distribution (grey background), we discover that almost all GWs with smaller horizontal wavelengths $(<300 \mathrm{~km})$ are located within region (I). The density distributions reveal three preferred propagation directions (Fig. 7d). The FWHMs of the three peaks are given in Table 1. We treat each peak as a GW packet. A first packet propagates southeastward at about 17:00 UT, and a second packet travels northwestward at 20:00 UT. The latter either turns northeastward after 22:00 UT or a third packet appears. The background wind in the propagation direction is negative at all times for all waves (Fig. 8b), indicating wave propagation against the mean flow. In accordance with the propagation against the background wind, intrinsic periods are smaller than observed periods (Fig. 8b). Again, almost all small-period GWs with intrinsic periods below $0.6 \mathrm{~h}$ are found in region (I). Our WAPITI algorithm identifies mainly upward-propagating waves in lidar data, with the majority of vertical wavelengths between 17 and $25 \mathrm{~km}$ (Fig. 9b). The probability density distribution shows another broader peak between 10 and $43 \mathrm{~km}$, affiliated with downward-propagating waves. Figure $9 a$ and $b$ also show vertical wavelengths larger than $50 \mathrm{~km}$. We emphasize that these large values are retrieved only in the altitude range of the OH layer $(82.5-91.1 \mathrm{~km})$. Phase lines that are locally very steep (e.g. due to vertical wind shear) seem to exhibit very large vertical wavelengths. Upward- and downwardpropagating waves alternate throughout the night. The reason for this may be refraction levels or vertical wind shear. The calculated vertical wavelengths in Fig. 9d peak between 7 and $50 \mathrm{~km}$. The peaks identified in lidar data overlap largely with this range (Fig. 9b).

In summary, region (I) contains small-period waves travelling predominantly northwestward against the background wind, resulting in a Doppler shift of intrinsic periods to larger observed periods. These small-period waves dominate the density distributions for horizontal wavelengths $<300 \mathrm{~km}$ and intrinsic periods $<0.6 \mathrm{~h}$. In AMTM time-lapse videos, we observe GW breaking at 21:00 UT. This coincides with the appearance of large amplitudes in spectral region (I) in the AMTM wavelet spectrum. One explanation could be that small-period GWs are generated by longer-period GWs breaking at 21:00 UT. Amplitudes in the CORAL spectrum confirm the presence of large-period waves. Another possibility is a change of background conditions (e.g. induced by tides) at 21:00 UT in such a way that afterwards, small-period GWs can be detected by the AMTM. The rapid change of sign of the vertical wavelength shows that this region is dominated by vertical wind shear, i.e. $\frac{\partial u}{\partial z} \neq 0$. Alternating $\lambda_{z}$ may also be a sign for reflection of waves (ducted waves). 


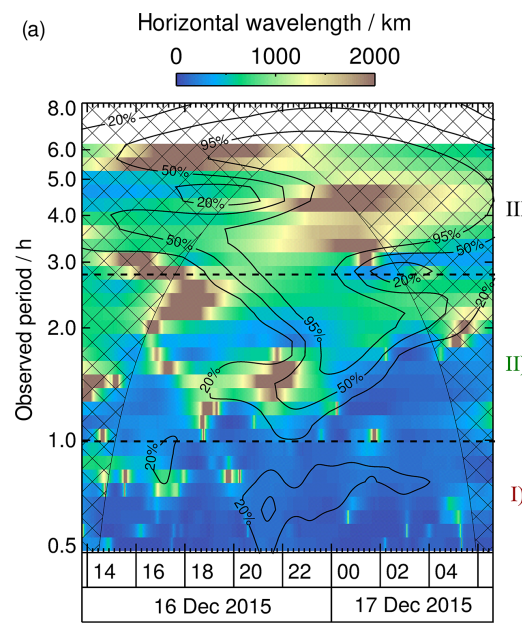

(c)

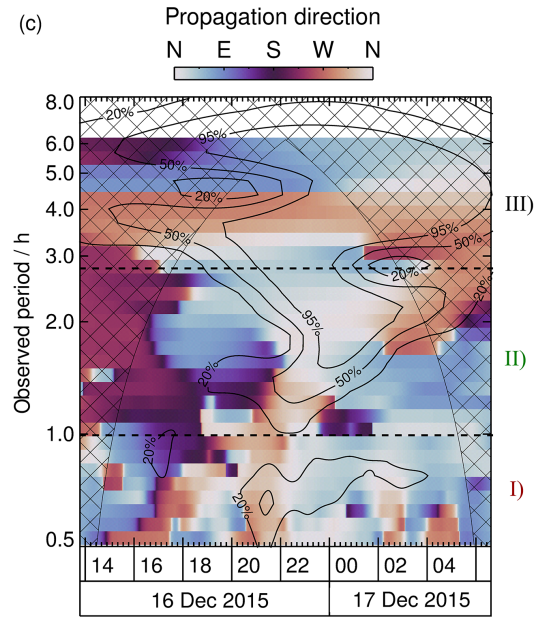

(b)

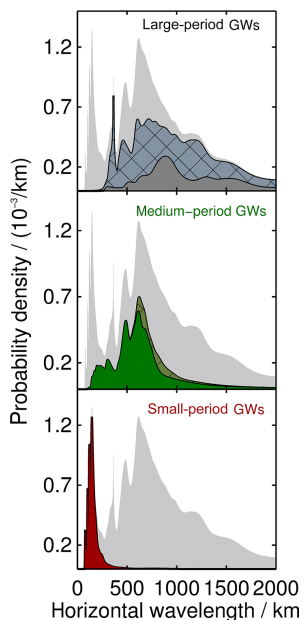

(d)

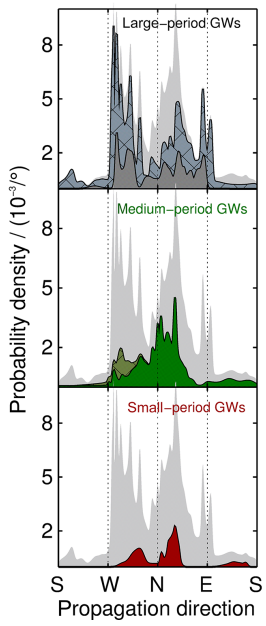

Figure 7. (a) Horizontal wavelengths observed by the AMTM as function of time and observed period. The hatched area represents the COI. Contour lines mark the $20 \%, 50 \%$ and $95 \%$ significance levels. (b) Density distributions for significance levels $>20 \%$ for region I (red), region II (green) and region III (grey). The grey distribution in the background shows the total probability density distribution of all values with significance level $>20 \%$. Hatched areas indicate values within the COI. (c) Same as (a) for propagation directions based on horizontal wavelengths. (d) Density distributions for each region as in (b). Dotted lines mark the cardinal directions.

The comparison of absolute values of vertical wavelengths from the two retrievals shows that both methods are in good agreement. However, vertical wavelengths retrieved by the WAPITI algorithm have a narrower distribution than the values we derived from the dispersion relation. Discrete peaks in the density distribution of the propagation direction help to distinguish between GW packets.

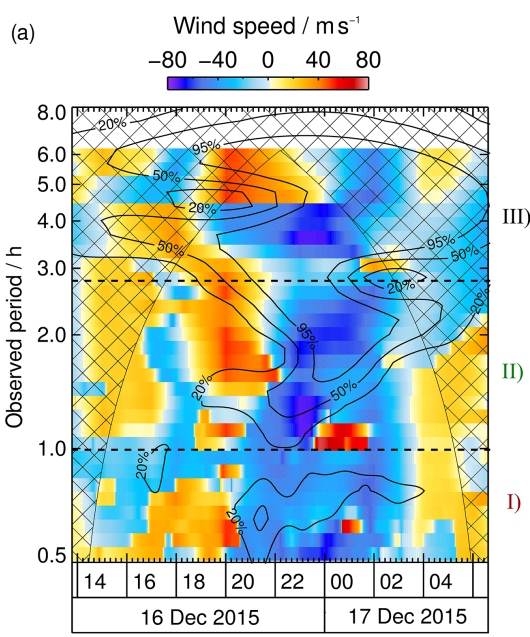

(b)
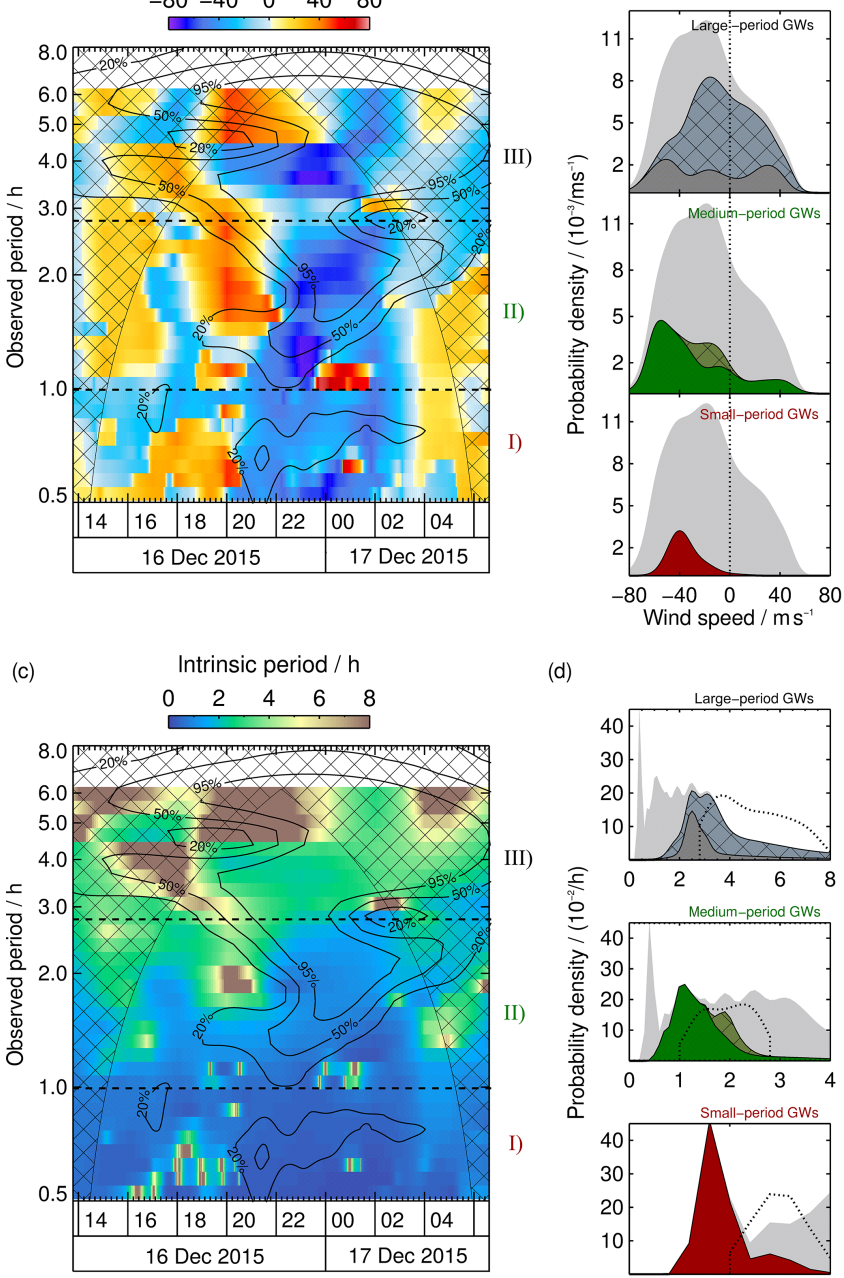

(d)

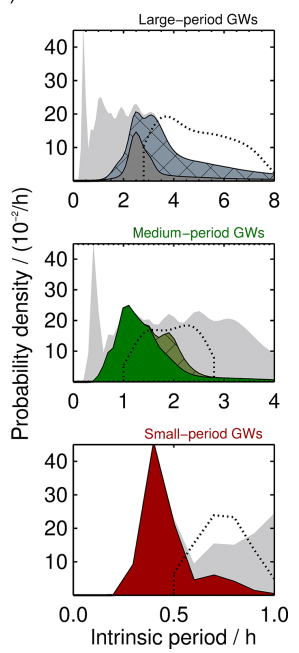

Figure 8. (a) Same as Fig. 7a but for horizontal wind speeds in the direction of horizontal propagation. (b) Density distributions for each region as in Fig. 7b. The dotted line represents zero wind speed. (c) Same as Fig. 7a but for intrinsic periods based on horizontal wavelengths and the background wind. (d) Density distributions for each region as in Fig. 7b. Additionally, the distributions of observed periods are given (dashed lines).

\subsection{Medium-period gravity waves}

Region (II) comprises observed periods between 1.0 and $2.8 \mathrm{~h}$. The peaks in the global wavelet spectra of CORAL (Fig. 4b) and the AMTM (Fig. 4e) are slightly shifted. For CORAL, the peak lies at $1.8 \mathrm{~h}$, while it is at $2.2 \mathrm{~h}$ for the AMTM. This difference may result from the different sensitivities of the instruments or the variability in the $\mathrm{OH}$ layer thickness and altitude. In comparison to region (I) we find a large overlapping area of statistical significance in both spectra. Figure $4 c$ shows a slight increase in spectral ampli- 

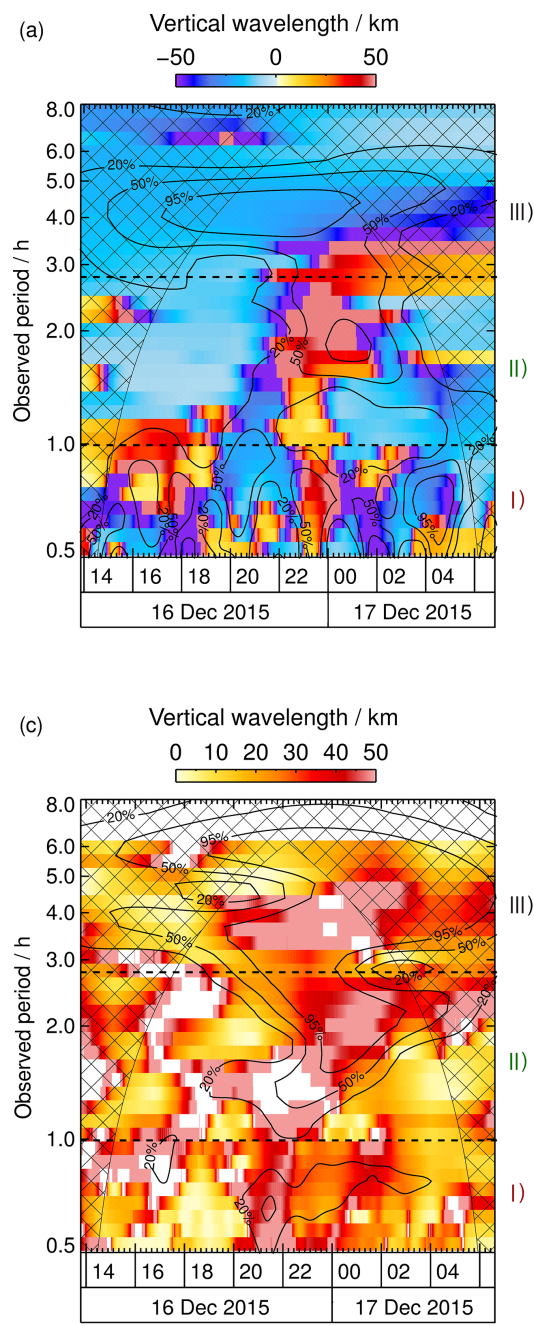

(b)

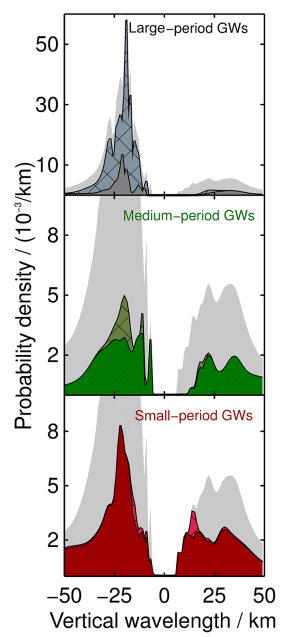

(d)

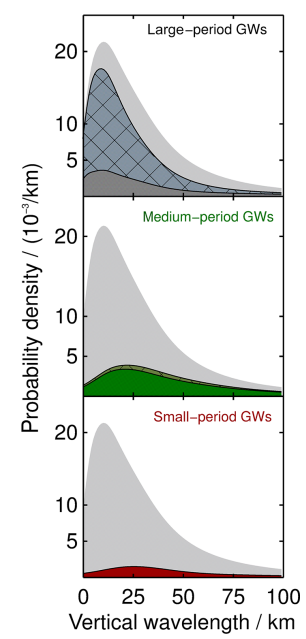

Figure 9. (a) Same as Fig. 7a but for vertical wavelengths derived from lidar data. Positive vertical wavelengths indicate downwardpropagating waves (upward-slanted phase lines), and negative vertical wavelengths indicate upward-propagating waves (downwardslanted phase lines). (b) Density distributions for each region as in Fig. 7b. (c) Same as Fig. 7a but for vertical wavelengths retrieved from the dispersion relation. White gaps indicate a complex wavelength. (d) Density distributions for each region as in Fig. 7b.

tude with altitude compared to region (I), suggesting growing wave amplitudes.

Most of the horizontal wavelengths lie between 443 and $747 \mathrm{~km}$ (Fig. 7b). Taking the values within the COI into account does not alter, in general, the shape of the peak. When we compare the distribution of region (II) with the total density distribution (grey background), we see that region (II) contributes to all wavelengths. However, its contribution to larger wavelengths is weaker. Sometimes phase lines are locally very steep in both keograms, and therefore $\lambda_{\mathrm{h}}$ attains large values. One example is evident at 22:00 UT

for the $1.5 \mathrm{~h}$ observed period. After 23:00 UT, $\lambda_{\mathrm{h}}$ decreases rapidly within $1 \mathrm{~h}$, from 2000 to $200 \mathrm{~km}$. This is a clear sign for a gradient in the horizontal wind field, as $\frac{\partial \lambda_{\mathrm{h}}}{\partial t} \sim \frac{\partial u}{\partial x}$ (Marks and Eckermann, 1995; Stober et al., 2018). As evident from Fig. 7c the propagation direction is first westward and becomes northeastward later. Our explanation is that the waves appear to rotate in AMTM data due to a horizontal wind gradient. This leads to bent phase lines in the temperature reconstructions which are identified as very large horizontal wavelengths. The dominant propagation direction is northward to northeastward. Later, waves turn westward. The northward propagation results in negative wind speeds (Fig. 8b). Only small spectral areas comprising waves with an eastward component experience positive wind speeds. Wind speeds from region (II) dominate the total density distribution (grey background) between -80 and $-50 \mathrm{~m} \mathrm{~s}^{-1}$. As we have seen in region (I), a propagation against the background wind leads to a Doppler shift of intrinsic periods towards larger observed periods. This is in general also the case in region (II), where the majority of waves with intrinsic periods between 1.1 and $1.8 \mathrm{~h}$ are Doppler-shifted towards observed periods between 1.0 and $2.8 \mathrm{~h}$ (Fig. 8c). Values within the COI slightly broaden the distribution. Intrinsic periods from region (II) dominate the total density distribution (grey background) between 0.6 and $2.1 \mathrm{~h}$. Most of the vertical wavelengths derived from lidar data lie between 11 and $36 \mathrm{~km}$ (Fig. 9b) and are affiliated with upward-propagating waves. We identify two additional peaks between 6 and $8 \mathrm{~km}$ (upward) and 16 and $45 \mathrm{~km}$ (downward). On the left-hand side of Fig. 9a, we find that waves first propagate upward and then turn downward at 22:00 UT and back upward at $\sim$ 02:00 UT. As mentioned in region (I) the change of propagation direction indicates vertical wind shear or levels of reflection (ducted waves). The distribution of vertical wavelengths estimated using the dispersion relation shows an even broader peak, as in region (I), with values between 5 and $54 \mathrm{~km}$ (Fig. 9b). Vertical wavelengths within the COI increase slightly the probability density at the position of the peak. Absolute values of the density distribution of $\lambda_{z}$ and the FWHM of the respective peaks are in general agreement (Fig. 9b and d and Tables 1 and 2). To note is the white gap between 21:00 and 23:00 UT in Fig. 9c. In this area the condition for a real $\lambda_{z}$ is not fulfilled. Waves in this area either do not propagate or the vertical wind shear is underestimated.

We state that the appearance of GWs in region (II) coincides with a wave breaking event at 21:00 UT and a strengthening of the mean flow. The retrieved parameters show a large variability which may follow from a non-uniform wind speed distribution within the FOV of the AMTM and altitude range of the $\mathrm{OH}$ layer. Interestingly not all parts of the $\mathrm{GW}$ spectrum react in the same way to the changing background wind. 


\subsection{Large-period gravity waves}

A wide range of observed periods from 2.8 to $6.5 \mathrm{~h}$ is detected in spectral region (III). When we compare the global wavelet spectra of CORAL (Fig. 4b) and the AMTM (Fig. 4e) we find the most prominent peak at the $4.2 \mathrm{~h} \mathrm{ob-}$ served period in the CORAL spectrum and a slightly shifted peak at $3.8 \mathrm{~h}$ in the AMTM spectrum. We assert that both instruments are sensitive to waves in this spectral domain, although there are some striking exceptions. The contour line of the $20 \%$ significance level in the AMTM spectrum covers the whole night and comprises observed periods between 2.8 and $8.0 \mathrm{~h}$. The statistically significant area in the CORAL spectrum is more focused and comprises observed periods between 2.8 and $6.0 \mathrm{~h}$. Right at the position of maximum amplitude in the CORAL spectrum, we find a gap in the spectrum of the AMTM. This gap results most probably from waves with small vertical wavelengths which cannot be detected by the AMTM. Another explanation is an $\mathrm{OH}$ layer altitude that is higher or lower than assumed. Looking at Fig. $4 \mathrm{c}$ we find a peak shifting from the $3.5 \mathrm{~h}$ observed period at an $82 \mathrm{~km}$ altitude to $4.5 \mathrm{~h}$ at $90 \mathrm{~km}$. This behaviour might be indicative of separate waves at different altitudes, or the same wave being Doppler-shifted to multiple observed periods at different altitudes, which then implies a vertical gradient in horizontal wind speed. Such a vertical gradient is supported by SLICE meteor wind measurements (Fig. 3). From $\frac{\partial \lambda_{z}}{\partial t} \sim \frac{\partial u}{\partial z}$, we expect a changing vertical wavelength with time, as we find a vertical gradient in horizontal wind speed. Figures $9 \mathrm{a}$ and $\mathrm{c}$ show a changing $\lambda_{z}$.

We find a rather broad distribution of horizontal wavelengths, with a peak between 739 and $1032 \mathrm{~km}$ (Fig. 7b). To note are two areas reaching at least a $2000 \mathrm{~km}$ horizontal wavelength. A major peak is located at 01:00 UT and the $4.4 \mathrm{~h}$ observed period, and a smaller peak is located at 01:30 UT and the $3.3 \mathrm{~h}$ observed period. As mentioned above, phase lines appear to be locally steep in the temperature reconstructions likely due to a gradient in horizontal wind. At the same time, waves appear to be rotating in propagation direction. Both peaks in Fig. 7a show a rapid turning of waves, with an angular change of $>90^{\circ}$ within $2 \mathrm{~h}$. Overall, considering the distribution of propagation directions we identify three different GW packets (Fig. 7d). The first comprises observed periods between 2.8 and $3.5 \mathrm{~h}$ and propagates in a northward-northeastward direction between 18:00 and 01:00 UT. The second packet exhibits observed periods between 3.5 and $4.5 \mathrm{~h}$, propagates westward, and turns northward during the night. Between the 4.5 and $6.0 \mathrm{~h}$ observed period, we find a third wave packet propagating eastward and turning northward during the duration of the measurement. Interesting to observe is the bidirectionality of the $\mathrm{GW}$ packets, which is also reflected in the distribution of wind speeds. Most of the waves propagate against the wind, i.e. wind speeds are negative, but there is also a large part of waves travelling with the wind (Fig. 8b).
The first GW packet experiences tailwind at 18:00 UT, but at 19:00 UT the wind turns and strengthens negative values. Negative winds are present for the second GW packet between 20:00 and 04:00 UT as well. The third packet experiences positive and decreasing wind speeds between 18:00 and 01:00 UT. Values inside the COI modify the distribution such that it changes from a plateau to a peak shape. Wind speeds from region (III) dominate the total density distribution (grey background) between -50 and $80 \mathrm{~m} \mathrm{~s}^{-1}$. Figure $8 \mathrm{~b}$ shows that most of the waves outside the COI are Dopplershifted from small intrinsic periods between 2.5 and $3.1 \mathrm{~h}$ to larger observed periods between 2.8 and $6.5 \mathrm{~h}$. Intrinsic periods from region (III) dominate the total density distribution (grey background) between 2.1 and $8.0 \mathrm{~h}$. Based on lidar data the WAPITI algorithm identifies a majority of vertical wavelengths between 19 and $22 \mathrm{~km}$ (Fig. 9a). Vertical wavelengths from region (III) dominate the total density distribution (grey background) for negative values. We find two smaller peaks between 12 and $14 \mathrm{~km}$ (upward) and 24-40 km (downward). This is in good agreement with values retrieved using the dispersion relation (Fig. 9b). Due to large uncertainties in the calculation of vertical wavelengths, the density distribution is very broad. Hence, values for $\lambda_{z}$ smaller than the $\mathrm{OH}$ layer thickness are also retrieved. In Fig. 9c we find another white gap, indicating a complex vertical wave number. This area coincides with a domain of extremely large horizontal wavelengths (Fig. 7a) and fast wave rotation (Fig. 7c). As mentioned above, this is an indication for a gradient in the horizontal wind field. Vertical wavelengths are relatively small and slowly increasing, which is in agreement with the nondetection by the AMTM in the beginning of the measurement due to the lack of sensitivity to small vertical wavelengths. At the same time the variation in $\lambda_{z}$ provides evidence for a vertical wind shear. We rearrange the ray-tracing equations stated by Marks and Eckermann (1995), yielding

$\frac{\partial u}{\partial z}=\frac{\lambda_{\mathrm{h}}}{\lambda_{z}^{2}} \frac{\mathrm{d} \lambda_{z}}{\mathrm{~d} t}$,

with $u$ being the horizontal wind speed in an arbitrary direction. $\lambda_{\mathrm{h}}$ and $\lambda_{z}$ are averaged at an observed period of $4 \mathrm{~h}$ between 20:00 and 03:00 UT, i.e. a time span in which both wavelet spectra exhibit large significance levels. The vertical wavelength changes from -15 to $-30 \mathrm{~km}$ within this time span. Hence, $\frac{\partial u}{\partial z}=\frac{900 \mathrm{~km}}{20^{2} \mathrm{~km}^{2}} \frac{15 \mathrm{~km}}{7 \mathrm{~h}}=1.3 \frac{\mathrm{m} \mathrm{s}^{-1}}{\mathrm{~km}}$. When we multiply this value by the thickness of the $\mathrm{OH}$ layer, we get a total difference in wind speed of $\Delta u=11.5 \mathrm{~m} \mathrm{~s}^{-1}$. The mean absolute wind speed retrieved from SLICE between 20:00 and 03:00 UT increases from $41 \mathrm{~m} \mathrm{~s}^{-1}$ at $82 \mathrm{~km}$ to $51 \mathrm{~ms} \mathrm{~s}^{-1}$ at $90 \mathrm{~km}$ (Fig. 3). This value is in very good agreement with our estimate. We conclude that with the help of our method, we are able to derive vertical wind gradients and possibly even horizontal gradients.

In region (III) we identify two GW packets moving in opposite directions (westward and eastward) turning slowly 
northward. Both propagate upward. These changes of propagation direction are most probably due to wind gradients. The existence of large-period waves is one condition for the supposed gravity wave breaking at 21:00 UT. Another cause for gravity wave breaking at mesospheric altitudes could be interaction with tides.

In summary, we demonstrated that our analysis is capable of determining the full set of GW parameters covering a wide range of values that are known to be typical for gravity waves. Typical values for $\lambda_{\mathrm{h}}$ in airglow data are in the range of 10-200 km (Nakamura et al., 2003; Diettrich et al., 2005; Matsuda et al., 2014; Lu et al., 2015; Nyassor et al., 2018). By analysing keograms, Fritts et al. (2014) retrieve even larger $\lambda_{\mathrm{h}}$ values reaching $4000 \mathrm{~km}$. They decompose temperature perturbations into a few dominant modes and find a wide range of values for the horizontal wavelength (24$\sim 4000 \mathrm{~km})$, vertical wavelength $(17.6-\sim 30 \mathrm{~km})$, intrinsic period $(\sim 10 \mathrm{~min}-12 \mathrm{~h}$ ), intrinsic phase velocity (33 to $>$ $\left.200 \mathrm{~m} \mathrm{~s}^{-1}\right)$ and background wind $\left(\sim 14-51 \mathrm{~m} \mathrm{~s}^{-1}\right)$. Vertical wavelengths retrieved from lidar data are typically between 2 and $20 \mathrm{~km}$ (Kaifler et al., 2017). Values for $\lambda_{z}>50 \mathrm{~km}$ are an indication for ducted waves (Snively and Pasko, 2003).

\section{Conclusions}

In this study we combined three complementary data sets obtained from co-located instruments. Vertical temperature profiles by CORAL and the AMTM's horizontal temperature maps provide three-dimensional insight into the behaviour of GWs in the MLT region. Additional wind information provided by the SLICE meteor radar made it possible to investigate the intrinsic propagation of these GWs. Our newly developed WAPITI algorithm combines spectral filtering using wavelet analysis with a phase line identification algorithm. Based on this method, we were able to retrieve observed as well as intrinsic GW parameters with estimations of their uncertainties as a function of time and ground-relative period. This facilitates separation and characterization of GW packets without using the dispersion relation.

Although the sensitivities of the instruments differ, by comparing wavelet spectra, we confirm that AMTM and CORAL observed, in general, the same GWs. For the case study on 16-17 December 2015, the night started with largescale waves between the 3 and $5 \mathrm{~h}$ ground-relative period. At 21:00 UT wave breaking occurred, resulting in spectral broadening and creation of small-period waves. The mean flow turns in the southeastward direction and strengthens. The detected GWs propagate predominantly against this background wind in a northward direction, resulting in a Doppler shift of about $1 \mathrm{~h}$. The vertical wind shear caused a steepening of phase lines, i.e. an increase in vertical wavelengths. Additionally we find very large horizontal wavelengths and wave rotation, indicating a horizontal wind shear as well. We were not looking for isolated wave events but investigated all data sets, interpreting the observations as a superposition of several GWs. All retrieved parameters are highly variable in time and observed period. This provides evidence for a non-uniform wind field in space and time and points out the complex interaction between waves and the background flow. As only parts of the spectra are sensitive to wind gradients, we conclude that small-period waves see large-period ones as disturbances in the background. Only the distribution of propagation directions exhibited multiple discrete peaks which help to distinguish clearly between $\mathrm{GW}$ packets. The GW parameters can be used to calculate momentum fluxes, to perform forward and backward ray tracing, and to derive a horizontally resolved wind field. The largest uncertainty of intrinsic parameters derived with our method arises due to the unknown precise altitude and shape of the $\mathrm{OH}$ layer. A reliable method to determine the precise $\mathrm{OH}$ profile is needed in order to improve GW results and to allow for better differentiation between GW packets. We plan to automate our method and apply it to more case studies and eventually to the whole data set, with the goal of studying propagation and interaction of GWs with the mean flow from a statistical point of view. In order to assess spatial properties of GWs, we want to extend our analysis to the whole FOV of the imager.

Code and data availability. Lidar, radar and AMTM data sets are available as NetCDF files in HALO-DB at https://halo-db.pa.op. dlr.de/mission/109 (last access: 4 November 2019), entries 6457 to 6469. 


\section{Appendix A: Uncertainties}

In this section, we present uncertainty calculations for the retrieved parameters' horizontal wavelength, direction of propagation, intrinsic period, wind in propagation direction, wind shear, wind curvature and vertical wavelength derived from the dispersion relation. The uncertainty of the intrinsic period contains wind speed uncertainties $\Delta u_{0}$, which comprises three sources. First we average the Gaussian-weighted wind speed over an altitude range of $82-95 \mathrm{~km}$, with a FWHM of $8.6 \mathrm{~km}$ centred at $86.8 \mathrm{~km}$. This is the average altitude and thickness of the $\mathrm{OH}$ layer. As mentioned in Sect. 2.2, these parameters are variable; therefore it is possible that the $\mathrm{OH}$ layer is partly below $82 \mathrm{~km}$ or above $91 \mathrm{~km}$, and we do not average over the correct altitude range. Second, we calculate the wind speed in the direction of propagation, which is based on the estimated $\theta$. As $\theta$ may be inaccurate, there is some uncertainty in the projected wind speed as well. Finally, for the wind measurements itself, we assume uncertainties of $10 \mathrm{~m} \mathrm{~s}^{-1}$. As we average over at least three independent values, the uncertainty is reduced to $5.6 \mathrm{~m} \mathrm{~s}^{-1}$ :

$$
\begin{aligned}
\Delta \lambda_{x} & =\tau \Delta c_{x}, \\
\Delta \lambda_{y} & =\tau \Delta c_{y}, \\
\Delta \lambda_{\mathrm{h}} & =\left|\frac{\partial \lambda_{\mathrm{h}}}{\partial \lambda_{x}}\right| \Delta \lambda_{x}+\left|\frac{\partial \lambda_{\mathrm{h}}}{\partial \lambda_{y}}\right| \Delta \lambda_{y} \\
& =\frac{\left|\lambda_{y}\right| \Delta \lambda_{x}+\left|\lambda_{x}\right| \Delta \lambda_{y}}{\left(\lambda_{x}^{2}+\lambda_{y}^{2}\right)^{3 / 2}} . \\
\Delta \theta & =\frac{\left|\lambda_{y}\right| \Delta \lambda_{x}+\left|\lambda_{x}\right| \Delta \lambda_{y}}{\lambda_{y}^{2}+\lambda_{x}^{2}} . \\
\Delta \tau_{\mathrm{I}} & =\left|\frac{\partial \tau_{\mathrm{I}}}{\partial \lambda_{\mathrm{h}}}\right| \Delta \lambda_{\mathrm{h}}+\left|\frac{\partial \tau_{\mathrm{I}}}{\partial u_{0}}\right| \Delta u_{0} \\
& =\frac{\left|u_{0}\right| \Delta \lambda_{\mathrm{h}}+\left|\lambda_{\mathrm{h}}\right| \Delta u_{0}}{\left(c-u_{0}\right)^{2}} . \\
\Delta u_{0}(\theta) & =\left|\frac{\partial u_{0}}{\partial \theta}\right| \Delta \theta+\left|\frac{\partial u_{0}}{\partial U}\right| \Delta U+\left|\frac{\partial u_{0}}{\partial V}\right| \Delta V \\
& =|U \cos (\theta)-V \sin (\theta)| \Delta \theta+|\sin (\theta)| \Delta U \\
\Delta u_{0}^{\prime} & =\frac{\sqrt{2} \Delta u_{0}}{\mathrm{~d} z}, \quad+|\cos (\theta)| \Delta V . \\
\Delta u_{0}^{\prime \prime} & =\frac{2 \Delta u_{0}}{\mathrm{~d} z^{2}} . \\
\Delta \lambda_{z} & =\left|\frac{\partial \lambda_{z}}{\partial \lambda_{\mathrm{h}}}\right| \Delta \lambda_{\mathrm{h}}+\left|\frac{\partial \lambda_{z}}{\partial \tau_{\mathrm{I}}}\right| \Delta \tau_{\mathrm{I}}+\left|\frac{\partial \lambda_{z}}{\partial N}\right| \Delta N \\
& +\left|\frac{\partial \lambda_{z}}{\partial H_{\mathrm{S}}}\right| \Delta H_{\mathrm{S}}+\left|\frac{\partial \lambda_{z}}{\partial u_{0}^{\prime}}\right| \Delta u_{0}^{\prime}+\left|\frac{\partial \lambda_{z}}{\partial u_{0}^{\prime \prime}}\right| \Delta u_{0}^{\prime \prime} \\
& =\pi\left(\frac{\lambda_{z}}{2 \pi}\right)^{3}\left|\frac{8 \pi^{2}-2 N^{2} \tau_{\mathrm{I}}^{2}}{\lambda_{\mathrm{h}}}+\frac{u_{0}^{\prime} \tau_{\mathrm{I}}}{H_{\mathrm{S}}}-u_{0}^{\prime \prime} \tau_{\mathrm{I}}\right| \frac{\Delta \lambda_{\mathrm{h}}}{\lambda_{\mathrm{h}}^{2}} \\
& +\pi\left(\frac{\lambda_{z}}{2 \pi}\right)^{3}\left|\frac{2 N^{2} \tau_{\mathrm{I}}}{\lambda_{\mathrm{h}}}-\frac{u_{0}^{\prime}}{H_{\mathrm{s}}}+u_{0}^{\prime \prime}\right| \frac{\Delta \tau_{\mathrm{I}}}{\left|\lambda_{\mathrm{h}}\right|}
\end{aligned}
$$

$$
\begin{aligned}
& +\pi\left(\frac{\lambda_{z}}{2 \pi}\right)^{3}\left|\frac{2 N \tau_{\mathrm{I}}^{2}}{\lambda_{\mathrm{h}}^{2}}\right| \Delta N \\
& +\pi\left(\frac{\lambda_{z}}{2 \pi}\right)^{3}\left|\frac{1}{H_{\mathrm{S}}}+\frac{u_{0}^{\prime} \tau_{\mathrm{I}}}{\lambda_{\mathrm{h}}}\right| \frac{\Delta H_{\mathrm{S}}}{H_{\mathrm{s}}^{2}} \\
& +\pi\left(\frac{\lambda_{z}}{2 \pi}\right)^{3}\left|\frac{\tau_{\mathrm{I}}}{H_{\mathrm{S}} \lambda_{\mathrm{h}}}\right| \Delta u_{0}^{\prime} \\
& +\pi\left(\frac{\lambda_{z}}{2 \pi}\right)^{3}\left|\frac{\tau_{\mathrm{I}}}{\lambda_{\mathrm{h}}}\right| \Delta u_{0}^{\prime \prime} .
\end{aligned}
$$


Author contributions. RR developed the method, carried out all data analysis and wrote the majority of the paper. The idea was suggested by BK, who also supervised the work. NK provided the lidar data, wrote part of the Introduction and revised the paper. MR supervises the doctoral thesis of RR and made suggestions. PDP and MJT provided AMTM data. AK and ML provided wind data. RK supported the lidar and AMTM operation at Sodankylä.

Competing interests. The authors declare that they have no conflict of interest.

Acknowledgements. Robert Reichert thanks the German Research Foundation (DFG) for support through the research unit MultiScale Dynamics of Gravity Waves (MS-GWaves) grant RA 1400/61. This work was partly supported by the ARISE2 project (http: //arise-project.eu/, last access: 4 November 2019) within the Horizon 2020 programme of the European Commission. Natalie Kaifler was supported in the development of CORAL by the Helmholtz association within the project PD-206. The development and operations of AMTMs were funded by the AF DURIP grant F4962002-1-0258 and the NSF grants AGS-1061892 and AGS-1042227. The authors thank the personnel of the Finnish Meteorological Institute in Sodankylä, who provided assistance with the installation and operation of CORAL and the AMTM imager.

Financial support. This research has been supported by the German Research Foundation (DFG; grant no. RA 1400/6-1), the AF DURIP (grant no. F49620-02-1-0258), the NSF (grant nos. AGS-1061892 and AGS-1042227) and the European Commission Horizon 2020 programme (grant no. 653980).

The article processing charges for this open-access publication were covered by a Research

Centre of the Helmholtz Association.

Review statement. This paper was edited by Alyn Lambert and reviewed by two anonymous referees.

\section{References}

Alexander, M.: Interpretations of observed climatological patterns in stratospheric gravity wave variance, J. Geophys. Res.-Atmos., 103, 8627-8640, 1998.

Alexander, M. J. and Barnet, C.: Using Satellite Observations to Constrain Parameterizations of Gravity Wave Effects for Global Models, J. Atmos. Sci., 64, 1652-1665, https://doi.org/10.1175/JAS3897.1, 2007.

Alexander, S. P., Klekociuk, A. R., and Murphy, D. J.: Rayleigh lidar observations of gravity wave activity in the winter upper stratosphere and lower mesosphere above Davis, Antarctica $\left(69^{\circ} \mathrm{S}, 78^{\circ} \mathrm{E}\right)$, J. Geophys. Res.-Atmos., 116, D13, https://doi.org/10.1029/2010JD015164, 2011.
Baker, D. J. and Stair Jr, A.: Rocket measurements of the altitude distributions of the hydroxyl airglow, Physica Scripta, 37, 611622, https://doi.org/10.1088/0031-8949/37/4/021, 1988.

Baumgarten, G., Fiedler, J., Hildebrand, J., and Lübken, F.-J.: Inertia gravity wave in the stratosphere and mesosphere observed by Doppler wind and temperature lidar, Geophys. Res. Lett., 42, 10929-10936, https://doi.org/10.1002/2015GL066991, 2015.

Diettrich, J., Nott, G., Espy, P., Swenson, G., Chu, X., Taylor, M., Riggin, D., and Fritts, D.: High frequency atmospheric gravitywave properties using Fe-lidar and $\mathrm{OH}$-imager observations, Geophys. Res. Lett., 32, 9, 2005.

Dörnbrack, A., Gisinger, S., and Kaifler, B.: On the interpretation of gravity wave measurements by ground-based lidars, Atmosphere, 8, 49, https://doi.org/10.3390/atmos8030049, 2017.

Dörnbrack, A., Gisinger, S., Kaifler, N., Portele, T. C., Bramberger, M., Rapp, M., Gerding, M., Söder, J., Žagar, N., and Jelić, D.: Gravity waves excited during a minor sudden stratospheric warming, Atmos. Chem. Phys., 18, 12915-12931, https://doi.org/10.5194/acp-18-12915-2018, 2018.

Dunker, T.: The airglow layer emission altitude cannot be determined unambiguously from temperature comparison with lidars, Atmos. Chem. Phys., 18, 6691-6697, https://doi.org/10.5194/acp-18-6691-2018, 2018.

Ehard, B., Kaifler, B., Kaifler, N., and Rapp, M.: Evaluation of methods for gravity wave extraction from middle-atmospheric lidar temperature measurements, Atmos. Meas. Tech., 8, 46454655, https://doi.org/10.5194/amt-8-4645-2015, 2015.

Frey, H. U., Mende, S. B., Arens, J. F., McCullough, P. R., and Swenson, G. R.: Atmospheric gravity wave signatures in the infrared hydroxyl OH airglow, Geophys. Res. Lett., 27, 41-44, https://doi.org/10.1029/1999GL010695, 2000.

Fritts, D. C. and Alexander, M. J.: Gravity wave dynamics and effects in the middle atmosphere, Rev. Geophys., 41, 1, https://doi.org/10.1029/2001RG000106, 2003.

Fritts, D. C., Pautet, P.-D., Bossert, K., Taylor, M. J., Williams, B. P., Iimura, H., Yuan, T., Mitchell, N. J., and Stober, G.: Quantifying gravity wave momentum fluxes with Mesosphere Temperature Mappers and correlative instrumentation, J. Geophys. Res.-Atmos., 119, 13583-13603, https://doi.org/10.1002/2014JD022150, 2014.

Fritts, D. C., Smith, R. B., Taylor, M. J., Doyle, J. D., Eckermann, S. D., Dörnbrack, A., Rapp, M., Williams, B. P., Pautet, P.-D., Bossert, K., Criddle, N. R., Reynolds, C. A., Reinecke, P. A., Uddstrom, M., Revell, M. J., Turner, R., Kaifler, B., Wagner, J. S., Mixa, T., Kruse, C. G., Nugent, A. D., Watson, C. D., Gisinger, S., Smith, S. M., Lieberman, R. S., Laughman, B., Moore, J. J., Brown, W. O., Haggerty, J. A., Rockwell, A., Stossmeister, G. J., Williams, S. F., Hernandez, G., Murphy, D. J., Klekociuk, A. R., Reid, I. M., and Ma, J.: The Deep Propagating Gravity Wave Experiment (DEEPWAVE): An airborne and ground-based exploration of gravity wave propagation and effects from their sources throughout the lower and middle atmosphere, B. Am. Meteorol. Soc., 97, 425-453, 2016.

Fritts, D. C., Vosper, S. B., Williams, B. P., Bossert, K., Plane, J. M. C., Taylor, M. J., Pautet, P.-D., Eckermann, S. D., Kruse, C. G., Smith, R. B., Dörnbrack, A., Rapp, M., Mixa, T., Reid, I. M., and Murphy, D. J.: LargeAmplitude Mountain Waves in the Mesosphere Accompanying Weak Cross-Mountain Flow During DEEPWAVE Re- 
search Flight RF22, J. Geophys. Res.-Atmos., 123, 9992-10022, https://doi.org/10.1029/2017JD028250, 2018.

Gardner, C. S. and Taylor, M. J.: Observational limits for lidar, radar and airglow imager measurements of gravity wave parameters, J. Geophys. Res., 103, 6427-6437, https://doi.org/10.1029/97JD03378, 1998.

Hapgood, M. and Taylor, M. J.: Analysis of airglow image data, Annales de Geophysique, 38, 805-813, 1982.

Hauchecorne, A. and Chanin, M.-L.: Density and temperature profiles obtained by lidar between 35 and $70 \mathrm{~km}$, Geophys. Res. Lett., 7, 565-568, https://doi.org/10.1029/GL007i008p00565, 1980.

Hecht, J., Walterscheid, R., Fritts, D., Isler, J., Senft, D., Gardner, C., and Franke, S.: Wave breaking signatures in $\mathrm{OH}$ airglow and sodium densities and temperatures: 1. Airglow imaging, Na lidar, and MF radar observations, J. Geophys. Res.-Atmos., 102, 6655$6668,1997$.

Hocking, W., Fuller, B., and Vandepeer, B.: Real-time determination of meteor-related parameters utilizing modern digital technology, J. Atmos. Sol.-Terr. Phys., 63, 155-169, 2001.

Holton, J. R.: The role of gravity wave induced drag and diffusion in the momentum budget of the mesosphere, J. Atmos. Sci., 39, 791-799, 1982.

Holton, J. R.: The influence of gravity wave breaking on the general circulation of the middle atmosphere, J. Atmos. Sci., 40, $2497-$ 2507, 1983.

Hostetler, C. A. and Gardner, C. S.: Observations of horizontal and vertical wave number spectra of gravity wave motions in the stratosphere and mesosphere over the mid-Pacific, J. Geophys. Res.-Atmos., 99, 1283-1302, https://doi.org/10.1029/93JD02927, 1994.

Isler, J. R., Taylor, M. J., and Fritts, D. C.: Observational evidence of wave ducting and evanescence in the mesosphere, J. Geophys. Res.-Atmos., 102, 26301-26313, 1997.

Jia, M., Xue, X., Dou, X., Tang, Y., Yu, C., Wu, J., Xu, J., Yang, G., Ning, B., and Hoffmann, L.: A case study of A mesoscale gravity wave in the MLT region using simultaneous multiinstruments in Beijing, J. Atmos. Sol.-Terr. Phys., 140, 1-9, https://doi.org/10.1016/j.jastp.2016.01.007, 2016.

Kaifler, B., Kaifler, N., Ehard, B., Dörnbrack, A., Rapp, M., and Fritts, D. C.: Influences of source conditions on mountain wave penetration into the stratosphere and mesosphere, Geophys. Res. Lett., 42, 9488-9494, 2015.

Kaifler, N., Kaifler, B., Ehard, B., Gisinger, S., Dörnbrack, A., Rapp, M., Kivi, R., Kozlovsky, A., Lester, M., and Liley, B.: Observational indications of downward-propagating gravity waves in middle atmosphere lidar data, J. Atmos. Sol.-Terr. Phys., 162, 16-27, https://doi.org/10.1016/j.jastp.2017.03.003, 2017.

Kaifler, N., Kaifler, B., Wilms, H., Rapp, M., Stober, G., and Jacobi, C.: Mesospheric temperature during the extreme mid-latitude noctilucent cloud event on 18/19 July 2016, J. Geophys. Res.Atmos., 24, 13775-13789, 2018.

Koch, S. E., Jamison, B. D., Lu, C., Smith, T. L., Tollerud, E. I., Girz, C., Wang, N., Lane, T. P., Shapiro, M. A., Parrish, D. D., and Cooper, O. R.: Turbulence and Gravity Waves within an Upper-Level Front, J. Atmos. Sci., 62, 3885-3908, https://doi.org/10.1175/JAS3574.1, 2005.

Kogure, M., Nakamura, T., Ejiri, M. K., Nishiyama, T., Tomikawa, Y., and Tsutsumi, M.: Effects of Horizontal Wind Structure on a Gravity Wave Event in the Middle Atmosphere Over Syowa $\left(69^{\circ} \mathrm{S}, 40^{\circ} \mathrm{E}\right)$, the Antarctic, Geophys. Res. Lett., 45, 51515157, https://doi.org/10.1029/2018GL078264, 2018.

Li, Q., Xu, J., Liu, X., Yuan, W., and Chen, J.: Characteristics of mesospheric gravity waves over the southeastern Tibetan Plateau region, J. Geophys. Res.-Space, 121, 9204-9221, https://doi.org/10.1002/2016JA022823, 2016.

Li, Q., Yusupov, K., Akchurin, A., Yuan, W., Liu, X., and Xu, J.: First OH Airglow Observation of Mesospheric Gravity Waves Over European Russia Region, J. Geophys. Res.-Space, 123, 2168-2180, https://doi.org/10.1002/2017JA025081, 2018.

Lindzen, R. S.: Turbulence and stress owing to gravity wave and tidal breakdown, J. Geophys. Res.-Oceans, 86, 9707-9714, 1981

Lu, X., Liu, A. Z., Swenson, G. R., Li, T., Leblanc, T., and McDermid, I. S.: Gravity wave propagation and dissipation from the stratosphere to the lower thermosphere, J. Geophys. Res.Atmos., 114, D11, https://doi.org/10.1029/2008JD010112, 2009.

Lu, X., Chen, C., Huang, W., Smith, J. A., Chu, X., Yuan, T., Pautet, P.-D., Taylor, M. J., Gong, J., and Cullens, C. Y.: A coordinated study of $1 \mathrm{~h}$ mesoscale gravity waves propagating from Logan to Boulder with CRRL Na Doppler lidars and temperature mapper, J. Geophys. Res.-Atmos., 120, 9, https://doi.org/10.1002/2015JD023604, 2015.

Lukianova, R., Kozlovsky, A., and Lester, M.: Climatology and inter-annual variability of the polar mesospheric winds inferred from meteor radar observations over Sodankylä $\left(67^{\circ} \mathrm{N}, 26^{\circ} \mathrm{E}\right)$ during solar cycle 24, J. Atmos. Sol.-Terr. Phys., 171, 241-249, https://doi.org/10.1016/j.jastp.2017.06.005, 2018.

Mangognia, A., Swenson, G., Vargas, F., and Liu, A.: A mesospheric airglow multichannel photometer and an optical method to measure mesospheric AGW intrinsic parameters, J. Atmos. Sol.-Terr. Phys., 142, 108-119, https://doi.org/10.1016/j.jastp.2016.02.018, 2016.

Marks, C. J. and Eckermann, S. D.: A Three-Dimensional Nonhydrostatic Ray-Tracing Model for Gravity Waves: Formulation and Preliminary Results for the Middle Atmosphere, J. Atmos. Sci., 52, 1959-1984, https://doi.org/10.1175/15200469(1995)052<1959:ATDNRT>2.0.CO;2, 1995.

Matsuda, T. S., Nakamura, T., Ejiri, M. K., Tsutsumi, M., and Shiokawa, K.: New statistical analysis of the horizontal phase velocity distribution of gravity waves observed by airglow imaging, J. Geophys. Res.-Atmos., 119, 9707-9718, 2014.

Mzé, N., Hauchecorne, A., Keckhut, P., and Thétis, M. Vertical distribution of gravity wave potential energy from long-term Rayleigh lidar data at a northern middlelatitude site, J. Geophys. Res.-Atmos., 119, 12069-12083, https://doi.org/10.1002/2014JD022035, 2014.

Nakamura, T., Higashikawa, A., Tsuda, T., and Matsushita, Y.: Seasonal variations of gravity wave structures in $\mathrm{OH}$ airglow with a CCD imager at Shigaraki, Earth Planet. Space, 51, 897-906, https://doi.org/10.1186/BF03353248, 1999.

Nakamura, T., Aono, T., Tsuda, T., Admiranto, A., and Achmad, E.: Mesospheric gravity waves over a tropical convective region observed by $\mathrm{OH}$ airglow imaging in Indonesia, Geophys. Res. Lett., 30, 17, https://doi.org/10.1029/2003GL017619, 2003.

Nappo, C.: An Introduction to Atmospheric Gravity Waves, no. Bd. 1 in An Introduction to Atmospheric Gravity Waves, Academic Press, UAS, available at: https://books.google.de/books? id=I6KDVUU3myoC (last access: 4 November 2019), 2002. 
Nyassor, P. K., Buriti, R. A., Paulino, I., Medeiros, A. F., Takahashi, H., Wrasse, C. M., and Gobbi, D.: Determination of gravity wave parameters in the airglow combining photometer and imager data, Ann. Geophys., 36, 705-715, https://doi.org/10.5194/angeo-36-705-2018, 2018.

Pautet, P.-D., Taylor, M. J., Pendleton, W. R., Zhao, Y., Yuan, T., Esplin, R., and McLain, D.: Advanced mesospheric temperature mapper for high-latitude airglow studies, Appl. Opt., 53, 59345943, https://doi.org/10.1364/AO.53.005934, 2014.

Sedlak, R., Hannawald, P., Schmidt, C., Wüst, S., and Bittner, M.: High-resolution observations of small-scale gravity waves and turbulence features in the $\mathrm{OH}$ airglow layer, Atmos. Meas. Tech., 9, 5955-5963, https://doi.org/10.5194/amt-9-5955-2016, 2016.

Shiokawa, K., Otsuka, Y., and Ogawa, T.: Propagation characteristics of nighttime mesospheric and thermospheric waves observed by optical mesosphere thermosphere imagers at middle and low latitudes, Earth Planet. Space, 61, 479-491, https://doi.org/10.1186/BF03353165, 2009.

Sica, R. J. and Argall, P. S.: Seasonal and nightly variations of gravity-wave energy density in the middle atmosphere measured by the Purple Crow Lidar, Ann. Geophys., 25, 2139-2145, https://doi.org/10.5194/angeo-25-2139-2007, 2007.

Sivakumar, V., Rao, P. B., and Bencherif, H.: Lidar observations of middle atmospheric gravity wave activity over a low-latitude site (Gadanki, 13.5 $5^{\circ}$, 79.2 ${ }^{\circ} \mathrm{E}$ ), Ann. Geophys., 24, 823-834, https://doi.org/10.5194/angeo-24-823-2006, 2006.

Smith, S., Friedman, J., Raizada, S., Tepley, C., Baumgardner, J., and Mendillo, M.: Evidence of mesospheric bore formation from a breaking gravity wave event: Simultaneous imaging and lidar measurements, J. Atmos. Sol.-Terr. Phys., 67, 345-356, 2005.

Snively, J. B. and Pasko, V. P.: Breaking of thunderstormgenerated gravity waves as a source of short-period ducted waves at mesopause altitudes, Geophys. Res. Lett., 30, 24, https://doi.org/10.1029/2003GL018436, 2003.

Stober, G., Chau, J. L., Vierinen, J., Jacobi, C., and Wilhelm, S.: Retrieving horizontally resolved wind fields using multi-static meteor radar observations, Atmos. Meas. Tech., 11, 4891-4907, https://doi.org/10.5194/amt-11-4891-2018, 2018.

Stockwell, R. G., Lowe, R. P., and Mansinha, L.: Localized crossspectral analysis with phase-corrected wavelets, Proc. SPIE 2762, https://doi.org/10.1117/12.236027, 1996.

Suzuki, S., Shiokawa, K., Otsuka, Y., Ogawa, T., and Wilkinson, P.: Statistical characteristics of gravity waves observed by an allsky imager at Darwin, Australia, J. Geophysi. Res.-Atmos., 109, D20, https://doi.org/10.1029/2003JD004336, 2004.

Suzuki, S., Shiokawa, K., Otsuka, Y., Ogawa, T., Nakamura, K., and Nakamura, T.: A concentric gravity wave structure in the mesospheric airglow images, J. Geophys. Res.-Atmos., 112, D2, https://doi.org/10.1029/2005JD006558, 2007.

Swenson, G. R. and Mende, S. B.: OH emission and gravity waves (including a breaking wave) in all-sky imagery from Bear Lake, UT, Geophys. Res. Lett., 21, 2239-2242, https://doi.org/10.1029/94GL02112, 1994.

Swenson, G. R., Haque, R., Yang, W., and Gardner, C. S.: Momentum and energy fluxes of monochromatic gravity waves observed by an $\mathrm{OH}$ imager at Starfire Optical Range, New Mexico, J. Geophys. Res.-Atmos., 104, 6067-6080, https://doi.org/10.1029/1998JD200080, 1999.
Takahashi, H., Taylor, M. J., Pautet, P.-D., Medeiros, A. F., Gobbi, D., Wrasse, C. M., Fechine, J., Abdu, M. A., Batista, I. S., Paula, E., Sobral, J. H. A., Arruda, D., Vadas, S. L., Sabbas, F. S., and Fritts, D. C.: Simultaneous observation of ionospheric plasma bubbles and mesospheric gravity waves during the SpreadFEx Campaign, Ann. Geophys., 27, 1477-1487, https://doi.org/10.5194/angeo-27-1477-2009, 2009.

Tang, J., Kamalabadi, F., Liu, A. Z., and Swenson, G. R.: Extraction of momentum flux of monochromatic gravity waves using spectroscopic imaging, in: IGARSS 2003, 2003 IEEE International Geoscience and Remote Sensing Symposium, Proceedings (IEEE Cat. No. 03CH37477), 6, 3961-3963, 2003.

Taylor, M. J., Turnbull, D., and Lowe, R.: Spectrometric and imaging measurements of a spectacular gravity wave event observed during the ALOHA-93 campaign, Geophys. Res. Lett., 22, 28492852, 1995.

Taylor, M. J., Pautet, P.-D., Medeiros, A. F., Buriti, R., Fechine, J., Fritts, D. C., Vadas, S. L., Takahashi, H., and São Sabbas, F. T.: Characteristics of mesospheric gravity waves near the magnetic equator, Brazil, during the SpreadFEx campaign, Ann. Geophys. 27, 461-472, https://doi.org/10.5194/angeo-27-461-2009, 2009.

Thurairajah, B., Collins, R. L., Harvey, V. L., Lieberman, R. S., Gerding, M., Mizutani, K., and Livingston, J. M.: Gravity wave activity in the Arctic stratosphere and mesosphere during the 2007-2008 and 2008-2009 stratospheric sudden warming events, J. Geophys. Res.-Atmos., 115, D3, https://doi.org/10.1029/2010JD014125, 2010.

Torrence, C. and Compo, G. P.: A Practical Guide to Wavelet Analysis, B. Am. Meteorol. Soc., 79, 61-78, https://doi.org/10.1175/15200477(1998)079<0061:APGTWA>2.0.CO;2, 1998.

Vargas, F., Swenson, G., Liu, A., and Pautet, D.: Evidence of the excitation of a ring-like gravity wave in the mesosphere over the Andes Lidar Observatory, J. Geophys. Res.-Atmos., 121, 88968912, 2016.

Vincent, R. and Reid, I.: HF Doppler measurements of mesospheric gravity wave momentum fluxes, J. Atmos. Sci., 40, 1321-1333, 1983.

Wagner, J., Dörnbrack, A., Rapp, M., Gisinger, S., Ehard, B., Bramberger, M., Witschas, B., Chouza, F., Rahm, S., Mallaun, C., Baumgarten, G., and Hoor, P.: Observed versus simulated mountain waves over Scandinavia - improvement of vertical winds, energy and momentum fluxes by enhanced model resolution?, Atmos. Chem. Phys., 17, 4031-4052, https://doi.org/10.5194/acp-17-4031-2017, 2017.

Walterscheid, R., Hecht, J., Vincent, R., Reid, I., Woithe, J., and Hickey, M.: Analysis and interpretation of airglow and radar observations of quasi-monochromatic gravity waves in the upper mesosphere and lower thermosphere over Adelaide, Australia $\left(35^{\circ} \mathrm{S}, 138^{\circ} \mathrm{E}\right)$, J. Atmos. Sol.-Terr. Phys., 61, 461-478, https://doi.org/10.1016/S1364-6826(99)00002-4, 1999.

Wilson, R., Chanin, M. L., and Hauchecorne, A.: Gravity waves in the middle atmosphere observed by Rayleigh lidar: 2. Climatology, J. Geophys. Res.-Atmos., 96, 5169-5183, https://doi.org/10.1029/90JD02610, 1991.

Witschas, B., Rahm, S., Dörnbrack, A., Wagner, J., and Rapp, M.: Airborne Wind Lidar Measurements of Vertical and Horizontal Winds for the Investigation of Orographically In- 
duced Gravity Waves, J. Atmos. Ocean. Tech., 34, 1371-1386, https://doi.org/10.1175/JTECH-D-17-0021.1, 2017.

Yuan, T., Heale, C. J., Snively, J. B., Cai, X., Pautet, P.-D., Fish, C., Zhao, Y., Taylor, M. J., Pendleton Jr, W. R., Wickwar, V., and Mitchell, N. J.: Evidence of dispersion and refraction of a spectrally broad gravity wave packet in the mesopause region observed by the Na lidar and Mesospheric Temperature Mapper above Logan, Utah, J. Geophys. Res.-Atmos., 121, 579-594, 2016.
Zhang, F., Davis, C. A., Kaplan, M. L., and Koch, S. E.: Wavelet analysis and the governing dynamics of a large-amplitude mesoscale gravity-wave event along the East Coast of the United States, Q. J. Roy. Meteorol. Soc., 127, 2209-2245, https://doi.org/10.1002/qj.49712757702, 2001.

Zhao, R., Dou, X., Xue, X., Sun, D., Han, Y., Chen, C., Zheng, J., Li, Z., Zhou, A., Han, Y., Wang, G., and Chen, T.: Stratosphere and lower mesosphere wind observation and gravity wave activities of the wind field in China using a mobile Rayleigh Doppler lidar, J. Geophys. Res.-Space, 122, 88478857, https://doi.org/10.1002/2016JA023713, 2017. 